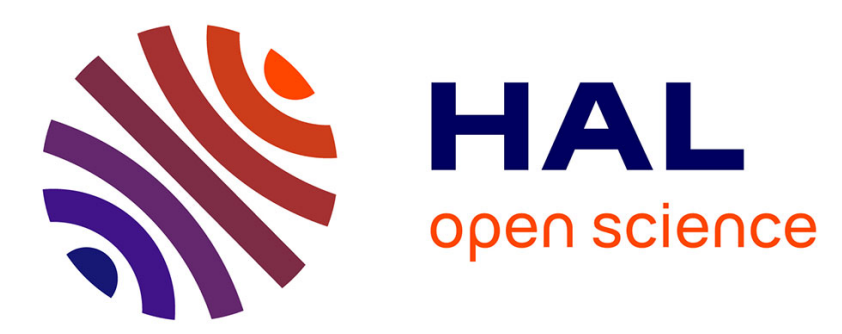

\title{
Mathematical modelling of a robust inspection process plan: Taguchi and Monte Carlo methods
}

\author{
Mehrdad Mohammadi, Ali Siadat, Jean-Yves Dantan, Reza
}

Tavakkoli-Moghaddam

\section{- To cite this version:}

Mehrdad Mohammadi, Ali Siadat, Jean-Yves Dantan, Reza Tavakkoli-Moghaddam. Mathematical modelling of a robust inspection process plan: Taguchi and Monte Carlo methods. International Journal of Production Research, 2014, 53 (7), pp.2202-2224. 10.1080/00207543.2014.980460 . hal01794852

\section{HAL Id: hal-01794852 https://imt-atlantique.hal.science/hal-01794852}

Submitted on 30 Mar 2020

HAL is a multi-disciplinary open access archive for the deposit and dissemination of scientific research documents, whether they are published or not. The documents may come from teaching and research institutions in France or abroad, or from public or private research centers.
L'archive ouverte pluridisciplinaire HAL, est destinée au dépôt et à la diffusion de documents scientifiques de niveau recherche, publiés ou non, émanant des établissements d'enseignement et de recherche français ou étrangers, des laboratoires publics ou privés. 


\title{
Mathematical modelling of a robust inspection process plan: Taguchi and Monte Carlo methods
}

\author{
Mehrdad Mohammadi $^{\mathrm{a}, \mathrm{b} *}$, Ali Siadat ${ }^{\mathrm{a}}$, Jean-Yves Dantan ${ }^{\mathrm{a}}$ and Reza Tavakkoli-Moghaddam ${ }^{\mathrm{b}}$ \\ ${ }^{a}$ LCFC, CER Metz - Arts et Métiers Paris Tech, Metz, France; ${ }^{b}$ School of Industrial Engineering, College of Engineering, University \\ of Tehran, Tehran, Iran
}

\begin{abstract}
This study develops a new optimisation framework for process inspection planning of a manufacturing system with multiple quality characteristics, in which the proposed framework is based on a mixed-integer mathematical programming (MILP) model. Due to the stochastic nature of production processes and since their production processes are sensitive to manufacturing variations; a proportion of products do not conform the design specifications. A common source of these variations is misadjustment of each operation that leads to a higher number of scraps. Therefore, uncertainty in misadjustment is taken into account in this study. A twofold decision is made on the subject that which quality characteristic needs what kind of inspection, and the time this inspection should be performed. To cope with the introduced uncertainty, two robust optimisation methods are developed based on Taguchi and Monte Carlo methods. Furthermore, a genetic algorithm is applied to the problem to obtain near-optimal solutions. To validate the proposed model and solution approach, several numerical experiments are done on a real industrial case. Finally, the conclusion is provided.
\end{abstract}

\section{Introduction}

Organisations in all industries that are somehow connected to supply chains have always encountered the challenge of designing and producing high-quality products. Producing these products needs efficient production systems in order to meet customer expectations. Therefore, developing an effective quality management system (QMS) has become one of the most important issues of these organisations, while neglecting the development of a capable QMS causes several inefficiencies (i.e. time and cost) across the supply chain (SC) and specially production party.

Since inefficiencies in time and cost, charges billions of dollars yearly to the organisations, several techniques have been developed to minimise the wastes across the SC. These inefficiencies may be the result of lacking an efficient system that ensures meeting quality requirements and customer expectations. One of the most effective approaches to handle these inefficiencies is designing a capable quality control system (QCS) that guarantees the products conform to determined specifications and they are able to meet customer expectations (Mirdamadi et al. 2011). On the other hand, dealing with inspection and planning an effective inspection process, QCS has always been the most efficient tool for decreasing waste and meeting customer expectations.

Inspection process planning (IPP) is an activity that determines which quality characteristics of a product should be inspected, where and when (Pfeiffer 2002; Zhao, Xu, and Xie 2009). In almost all manufacturing organisations, inspections are used during the processes to reach quality specifications instead of having an acceptance or a rejection inspection at the end. To achieve this goal, effective inspection planning should efficiently be integrated with the production processes.

Through an effective IPP, conformity (CI) and monitoring (MI) inspections are integrated with production processes. $\mathrm{CI}$ is a collective term used for a number of activities (e.g. testing, detection and certification) to specify if a product has met designed characteristics. In other words, CI ensures that a product has been correctly made based on the process plan and it is in the conformance with the design data. Hence, the main aim of CI in production is to avoid nonconformity and to minimise the risk of manufacturing products that have to be rejected instead of being sold (Hinrichs 2011). In CI, the production process is interrupted and all products (i.e. 100\% frequency) are checked whether they can meet standard specifications. Then, nonconforming products are removed from the production line and get scrapped. Since 
stopping the production process may not be cost-efficient, MI can be utilised as an indicator of process status. Using MI, corresponding features of the process (e.g. feed speed of a drilling machine, force and temperature, etc.), which significantly affect the final quality of the products, are checked for not deviating from their set value with lower frequency compared to CI (Chryssolouris 2005).

Manufacturers utilise CI and/or MI in their production processes based on the importance of products' characteristics. For instance, for characteristics that directly correspond to the product function and a malfunction may adversely affect the customer satisfaction; CI is recommended. On the other hand, using MI absolutely increases the capability of the processes and as a result decreases the deviation from standard tolerances as well as the number of defective characteristics. Both CI and MI eventually enhance customer satisfaction, while considering both CI and MI for all characteristics is the most reliable way to decrease the amount of scraps and correspondingly to increase customer satisfaction as much as possible. As a consequence of recourse limitations, this approach is not practical and increases the production cost as well as the final cost of products. Therefore, a trade-off between customer satisfaction and production cost should be conducted to determine whether setting inspections are cost-efficient or not.

Several techniques such as cost-benefit model (Savio 2012), simulation (Munch et al. 2002; Neu et al. 2002, 2003) and optimisation model (Hanne and Nickel 2005; Shiau 2003a) have been proposed to planning inspection processes. To the best of our knowledge, no study in the literature has proposed a mathematical programming model to provide an efficient process inspection planning. Thus, this study attempts to fill this gap by developing an optimisation framework for process inspection planning based on a mixed-integer linear programming (MILP) model that tries to make a tradeoff between cost and quality.

The rest of the study is organised as follows. Section 2 reviews the relevant literature. Section 3 shows problem description and the MILP model. Section 4 describes the applied robust optimisation methods. The solution algorithm is explained in Section 5. The experimental results are provided in Section 6. Finally, Section 7 concludes the study.

\section{Literature review}

This section reviews studies in which different optimisation techniques for process inspection planning are developed. Inspection planning problems have been studied by many researchers since the 1960s. Lindsay and Bishop (1964) proposed a basic conceptual model considering perfect inspection accuracy for workstations of attribute data (WAD). All the rejected items in their study were assumed to become scrapped. They also supposed that the inspection station can only check the outcome of the preceding operations right after they are performed. The extension of their study was proposed by White (1966) where the scrapped items are replaced with conforming ones. Hurst (1973) first planned an inspection process considering both type I and type II inspection errors. Peters and Williams (1984) provided five heuristic decision rules to make 'when decision'. Later, Yum and McDowell (1987) extended the formulation of this problem in the form of a mixed-integer linear programming model by adding the assumption of rework activity. Chakravarty and Shtub (1987) investigated the effects of set-up and inventory carrying costs on the inspection strategy (i.e. 'all or none' vs. 'partial inspection'). They suggested a shortest-path heuristic method to make decisions on when the inspections should be performed and how much the production lot sizes better to be.

Barad (1990) presented a solution-oriented technique based on the concept of break-even quality level. Viswanadham, Sharma, and Taneja (1996) mathematically modelled the 'when decision' in a multi-stage production system (MPS) and developed two stochastic search algorithms for solving the problem. One of the algorithms was based on simulated annealing (SA) and the other utilised genetic algorithm (GA) to search in solution space. Their algorithms were developed to determine the inspection time reflecting in a minimum expected total cost. Similarly, Bai and Yun (1996) constructed a cost model and a method for finding the optimal time of inspections and inspection level in an MPS. Briand, Laitenberger, and Wieczorek (1997) investigated the effectiveness of the inspection regarding the inspection team size during many experiments and in real-life settings. Lee and Unnikrishnan (1998) developed a mathematical model in order to solve the inspection allocation and assignment problems in an MPS in which different part types with distinctive machine visitation sequences were processed and inspections could be performed in one of the several inspection stations with possible inspection errors. Basili and Boehm (2001) considered the inspection planning as a key tool for finding defects and for ensuring the quality of a product. Two questions about the characteristics that should be inspected and the number of people that should participate in the inspection activity were answered in their study.

Lee and Kim (2001) proposed an optimisation model to integrate process planning and scheduling using simulationbased genetic algorithm. The performance measures were calculated based on process plan combinations by a simulation module instead of process plan alternatives. The calculated measures were used as inputs to a genetic algorithm in order to improve the solution quality until the scheduling objectives were satisfied. In similar integration, Hanne and Nickel (2005) developed a multi-objective inspection planning model considering objectives concerning the quality (number of 
defects), project make-span and costs. Their proposed model consisted of different phases such as coding, inspection, test and rework. This study also comprised the assignment of operations to people and the generation of a project schedule (Munch et al. 2002; Neu et al. 2002, 2003). Moreover, an evolutionary algorithm (EA) was presented to solve the proposed multi-objective inspection planning model.

Respecting the influence of inspection resource limitation on the inspection plan, Shiau (2002, 2003a) studied inspection resource assignment and considered inspection errors in an MPS. They considered a limited number of inspection stations for each class of inspection to plan the inspection process for satisfying customer requirements in the times that inspection errors happen due to rapid changes of tolerances. In addition, Shiau (2003b) studied inspectionallocation planning (IAP) in a multiple quality characteristic manufacturing system in which the production recourses were restricted and a limited number of inspection stations of each inspection station class were considered for solving IAP. This study solved IAP using a unit cost model in which the manufacturing capability, inspection capability and tolerance specified are simultaneously considered as well as a situation of unbalanced tolerance design. In a similar work, Shiau, Lin, and Chuang (2007) integrated production process and inspection planning. They inferred that higher performance of a production industry can be realised if process planning and inspection planning become integrated to cope with the limited manufacturing resources. They developed a genetic algorithm for solving large-scale problems. In a different work, Ferreira, Almeida, and Cavalcante (2009) proposed an optimisation model in which decisions on determining inspection intervals for MI under the failure of equipment are made considering the decision-maker preferences in cost and downtime.

Recently, Savio (2012) presented a methodology for the assessment of the economic impact of metrology in production by studying a cost-benefit model in which several mathematical formulations were developed to evaluate costs and benefits of inspection. Although, the evaluation of costs is facile, the calculation of benefits is challenging because of its nature and due to issues such as product reliability improvement and related reduction in warranty costs. With relation to these difficulties, a review of micro-economic facets in metrology was conducted emphasising on the fact that while costs are easy to calculate, benefits are more complex to assess and should be taken into account in the context of the entire production process (Kunzmann et al. 2005).

In regards to how experimental results are being affected by measurement uncertainty, several studies have been published that take the uncertainty in production metrology into account. Kallgren et al. (2003) reviewed the present status of the role of measurement uncertainty in CI assessment. Enthusiastic readers are referred to the recent review of uncertainty impact on production metrology done by Desimoni and Brunetti (2011).

\section{Problem description and mathematical formulation}

\subsection{Problem description}

Respecting the above-mentioned concerns in Section 1 regarding to make a trade-off between cost and quality, designing an effective IPP is a twofold decision: (1) which quality characteristics need what kind of inspection (known as 'which-what decision') and (2) when these characteristics should be inspected (known as 'when decision'). For the first decision, although the characteristics that have a more significant impact on product functionality and remarkably affect customer satisfaction should certainly be chosen to be inspected, all the characteristics cannot be inspected, since this action highly increases the inspection cost. The second decision about the stage of inspection is also challenging. Inspection of a characteristic can be done only in special stages during the overall process. During the inspection, the process cannot be stopped and in some occasions, accessibility to a specific characteristic is impossible unless in some specified stages. In addition, finding and eliminating nonconforming parts at the initial steps of the process will decrease the production cost as those parts do not go under further operations. Despite the fact that it is better to inspect each characteristic exactly after its related operation and before the beginning of following operation, but this will increase the number of inspection activities and consequently the total cost of inspection. For better understanding, consider a situation that each characteristic is inspected exactly after its related operation. Each inspection activity includes three steps as follows (1) removing the part from the machine, (2) inspecting and (3) setting up the parts for the next operation; hence, these steps are repeated for each characteristic. On the opposite site, when a set of characteristics is inspected at the same allowable stage, removing and setting up steps are done just once. Therefore, making which-what and when decisions are challenging issues and this study tries to address them.

\subsection{Mathematical formulation}

This section provides a mathematical formulation to model the problem mentioned in subsection 3.1 by making decisions on which quality characteristics need what kind of inspections and when these inspections should be 
performed. The objective function of this model attempts to minimise the total cost which consists of the costs of production, scrap, inspection (i.e. fixed and variable costs) and warranty. The warranty cost is the cost of selling nonconforming products.

Considering the decisions about the kind of inspection that is needed, two different strategies are assumed in the mathematical formulation. Firstly, we consider that each quality characteristic exactly needs one kind of inspection. Secondly, the first strategy is relaxed, and we assume that none, one or both MI and CI can be performed on each quality characteristic. Then, the first and the second strategies are called MI-or-CI and MI-and-CI strategies, respectively. In addition, knowing that inspection is imperfect, both error types I and II should be considered in the problem. Error type I refers to false rejections of conforming quality, while error type II represents false acceptance of nonconforming quality. These errors are taken into account to compute the amount of scrap at each stage of the inspection planning.

The necessary notations to design the mathematical model are as follows:

Sets:

$p, p^{\prime} \in\{1,2, \ldots, P+1\} \quad$ Set of operations

$k \in\{1,2, \ldots, K\} \quad$ Set of different quality characteristics

\section{Parameters:}

$f r_{p k}^{1} \quad$ Failure rate of operation $p$ for characteristic $k$ with MI

$f r_{p k}^{2} \quad$ Failure rate of operation $p$ for characteristic $k$ without MI

$d r_{p k}$

Detection rate of the conformity inspection assigned to operation $p$ for characteristic $k$

$\alpha_{p k}$

Error type $I$ for $\mathrm{CI}$ assigned to operation $p$ for characteristic $k$

$\beta_{p k}$

Error type II for CI assigned to operation $p$ for characteristic $k\left(\beta_{p k}=1-d r_{p k}\right)$

$n$

Total number of parts supplied to the production process

$p c_{p}$

$s c_{p}$

Operation $p$ production cost

Scrap cost of parts between operations $p$ and $p+1$

$w c_{k}$

Warranty cost caused by nonconforming quality characteristic $k$

$f m_{p k}$

$f c_{p k}$

Fixed cost of performing MI between operations $p$ and $p+1$ for quality characteristic $k$

$v m_{p k}$

Fixed cost of performing CI between operations $p$ and $p+1$ for quality characteristic $k$

$v c_{p k}$

$f_{s_{p}}$

Variable cost of performing MI between operations $p$ and $p+1$ for characteristic $k$

Variable cost of performing CI between operations $p$ and $p+1$ for characteristic $k$

$d_{p^{\prime} p}$

Fixed space cost per part of performing inspections between operations $p$ and $p+1$

1 if the operations $p^{\prime}$ and $p$ are dependent, 0 otherwise

$b_{p k} \quad 1$ if characteristic $k$ belongs to operation $p, 0$ otherwise

$m f_{k} \quad$ Monitoring frequency for characteristic $k$

$c f_{k} \quad$ Conformity frequency for characteristic $k$

$M \quad$ A big number

\section{Decision Variables:}

$C I_{p k} \quad 1$ if operation $p$ needs $\mathrm{CI}$ for characteristic $k$; 0 otherwise

$M I_{p k} \quad 1$ if operation $p$ needs MI for characteristic $k$; 0 otherwise

$X C_{p^{\prime} p}^{k} \quad 1$ if CI of operation $p^{\prime}$ for characteristic $k$ is performed after operation $p\left(p^{\prime} \leq p\right)$; 0 otherwise

$X M_{p^{\prime} p}^{k}$

$N_{p}$

1 if MI of operation $p^{\prime}$ for characteristic $k$ is performed after operation $p\left(p^{\prime} \leq p\right)$; 0 otherwise

$N M_{p k}$

$N C_{p k}$

$N S_{p}$

$S_{p k}$

$S_{p}$

$O F V_{D}$ Input number of parts entering operation $p$

Number of MIs between operations $p$ and $p+1$ for characteristic $k$

Number of CIs between operations $p$ and $p+1$ for characteristic $k$

1 if there is an inspection between operations $p$ and $p+1 ; 0$ otherwise

Number of scrap parts between operations $p$ and $p+1$ for characteristic $k$

Total number of scrap parts between operations $p$ and $p+1$

Objective function value of the deterministic approach 


\section{Auxiliary Variables:}

$N F R_{p k}$

$N X C_{p^{\prime} p}^{k}$

$N X M_{p^{\prime} p}^{k}$

$R X C_{p^{\prime} p}^{k}$

$R C I_{p k}$

$R M I_{p k}$

$N S N_{p}$

$N M I_{p k}$

$N C I_{p k}$
Number of scrap characteristics $k$ produced by operation $p$ with inspection

Linear form of $X C_{p^{\prime} p}^{k} \times N_{p}$

Linear form of $X M_{p^{\prime} p}^{k} \times N_{p}$

Linear form of $X C_{p^{\prime} p}^{k} \times N F R_{p^{\prime} k}$

Linear form of $N F R_{p k} \times C I_{p k}$

Linear form of $N F R_{p k} \times M I_{p k}$

Linear form of $N S_{p} \times N_{p}$

Linear form of $N_{p} \times M I_{p k}$

Linear form of $N_{p} \times C I_{p k}$

\subsubsection{Formulation of MI-or-CI strategy}

This section provides the mathematical modelling for the first strategy of inspection, in which all quality characteristics need exactly one kind of MI or CI.

$$
\begin{aligned}
\min O F V_{D}= & \sum_{p=1}^{P} p c_{p} N_{p}+\sum_{p=1}^{P} s c_{p} S_{p}+\sum_{p=1}^{P} \sum_{k=1}^{K} f c_{p k} N C I S_{p k}+\sum_{p=1}^{P} \sum_{k=1}^{K} c f_{k} V C_{p k} N X C_{p}+\sum_{p=1}^{P} \sum_{k=1}^{K} f m_{p k} N M I S_{p k} \\
& +\sum_{p=1}^{P} \sum_{k=1}^{K} m f_{k} V M_{p k} N X M_{p}+\sum_{p=1}^{P} f s_{p} N S N_{p}+\sum_{p=1}^{P} \sum_{k=1}^{K} w c_{k}\left(R C I_{p k} \beta_{p k}+R M I_{p k}\right)
\end{aligned}
$$

s.t.

$$
\begin{gathered}
\sum_{p=p^{\prime}}^{P} d_{p^{\prime} p} X C_{p^{\prime} p}^{k}=b_{p^{\prime} k} C I_{p^{\prime} k} \quad \forall p^{\prime}, k ; p^{\prime} \leq P \\
\sum_{p=p^{\prime}}^{P} d_{p^{\prime} p} X M_{p^{\prime} p}^{k}=b_{p^{\prime} k} M I_{p^{\prime} k} \quad \forall p^{\prime}, k ; p^{\prime} \leq P \\
C I_{p^{\prime} k}+M I_{p^{\prime} k}=b_{p^{\prime} k} \quad \forall p^{\prime}, k \\
N C r a p_{p k} \geq\left[R X C_{p^{\prime} p}^{k} \times d r_{p k}\right]+\left[\begin{array}{c}
\left.N X C_{p^{\prime} p}^{k} \times \alpha_{p k}-R X C_{p^{\prime} p}^{k} \times \alpha_{p k}\right]-\left[R X C_{p^{\prime} p}^{k} \times \beta_{p k}\right] \quad \forall p, p^{\prime}, k ; p, p^{\prime} \leq P \\
S_{p} \geq S_{p k} \quad \forall p, k ; p \leq P \\
N_{p k}^{1}+N C I_{p k} f r_{p k}^{2} \quad \forall p, k ; p \leq P \\
N M_{p k} \geq \sum_{p^{\prime}=1}^{P} X M_{p^{\prime} p}^{k} \quad \forall p, k ; p \leq P
\end{array}\right. \\
N_{p-1}-S_{p-1} \quad \forall p ; p \leq P+1
\end{gathered}
$$




$$
\begin{aligned}
& N C_{p k} \geq \sum_{p^{\prime}=1}^{P} X C_{p^{\prime} p}^{k} \quad \forall p, k ; p \leq P \\
& M \times N S_{p} \geq \sum_{p^{\prime}=1}^{P} \sum_{k=1}^{K}\left(X C_{p^{\prime} p}^{k}+X M_{p^{\prime} p}^{k}\right) \quad \forall p, p^{\prime}, k ; p, p^{\prime} \leq P \\
& N X C_{p^{\prime} p}^{k} \leq M \times X C_{p^{\prime} p}^{k} \quad \forall p, p^{\prime}, k ; p, p^{\prime} \leq P \\
& N X C_{p^{\prime} p}^{k} \leq N_{p^{\prime}} \quad \forall p, p^{\prime}, k ; p, p^{\prime} \leq P \\
& N X C_{p^{\prime} p}^{k} \geq N_{p^{\prime}}-M\left(1-X C_{p^{\prime} p}^{k}\right) \quad \forall p, p^{\prime}, k ; p, p^{\prime} \leq P \\
& N X M_{p^{\prime} p}^{k} \leq M \times X M_{p^{\prime} p}^{k} \quad \forall p, p^{\prime}, k ; p, p^{\prime} \leq P \\
& N X M_{p^{\prime} p}^{k} \leq N_{p^{\prime}} \quad \forall p, p^{\prime}, k ; p, p^{\prime} \leq P \\
& N X M_{p^{\prime} p}^{k} \geq N_{p^{\prime}}-M\left(1-X M_{p^{\prime} p}^{k}\right) \quad \forall p, p^{\prime}, k ; p, p^{\prime} \leq P \\
& N M I_{p^{\prime} k} \leq M \times M I_{p^{\prime} k} \quad \forall p, p^{\prime}, k ; p, p^{\prime} \leq P \\
& N M I_{p^{\prime} k} \leq N_{p^{\prime}} \quad \forall p, p^{\prime}, k ; p, p^{\prime} \leq P \\
& N M I_{p^{\prime} k} \geq N_{p^{\prime}}-M\left(1-M I_{p^{\prime} k}\right) \quad \forall p, p^{\prime}, k ; p, p^{\prime} \leq P \\
& N C I_{p^{\prime} k} \leq M \times C I_{p^{\prime} k} \quad \forall p, p^{\prime}, k ; p, p^{\prime} \leq P \\
& N C I_{p^{\prime} k} \leq N_{p^{\prime}} \quad \forall p, p^{\prime}, k ; p, p^{\prime} \leq P \\
& N C I_{p^{\prime} k} \geq N_{p^{\prime}}-M\left(1-C I_{p^{\prime} k}\right) \quad \forall p, p^{\prime}, k ; p, p^{\prime} \leq P \\
& R X C_{p^{\prime} p}^{k} \leq M \times X C_{p^{\prime} p}^{k} \quad \forall p, p^{\prime}, k ; p, p^{\prime} \leq P \\
& R X C_{p^{\prime} p}^{k} \leq N F R_{p^{\prime} k} \quad \forall p, p^{\prime}, k ; p, p^{\prime} \leq P
\end{aligned}
$$




$$
\begin{gathered}
R X C_{p^{\prime} p}^{k} \geq N F R_{p^{\prime} k}-M\left(1-X C_{p^{\prime} p}^{k}\right) \quad \forall p, p^{\prime}, k ; p, p^{\prime} \leq P \\
R C I_{p^{\prime} k} \leq M \times C I_{p^{\prime} k} \quad \forall p^{\prime}, k ; p^{\prime} \leq P \\
R C I_{p^{\prime} k} \leq N F R_{p^{\prime} k} \quad \forall p^{\prime}, k ; p^{\prime} \leq P \\
R C I_{p^{\prime} k} \geq N F R_{p^{\prime} k}-M\left(1-C I_{p^{\prime} k}\right) \quad \forall p^{\prime}, k ; p^{\prime} \leq P \\
R M I_{p^{\prime} k} \leq M \times M I_{p^{\prime} k} \quad \forall p^{\prime}, k ; p^{\prime} \leq P \\
R M I_{p^{\prime} k} \leq N F R_{p^{\prime} k} \quad \forall p^{\prime}, k ; p^{\prime} \leq P \\
R M I_{p^{\prime} k} \geq N F R_{p^{\prime}}-M\left(1-M I_{p^{\prime} k}\right) \quad \forall p^{\prime}, k ; p^{\prime} \leq P \\
N S N_{p^{\prime} p}^{k}, X M_{p^{\prime} p}^{k}, N S_{p}, C I_{p^{\prime} k}, M I_{p^{\prime} k} \in\{0,1\} \quad \forall p, p^{\prime} k ; p, p^{\prime} \leq P \\
N S_{p k}, \quad \forall p ; p \leq P \\
N S N_{p} \leq N_{p}, \quad \forall p ; p \leq P \\
N C_{p^{\prime} p}^{k}, N M_{p k}, N M_{p^{\prime} p}^{k}, N F R_{p k} R C I_{p^{\prime} k}, R M I_{p^{\prime} k}, N S N_{p}, N_{p} \geq 0 \quad \forall p^{\prime}, p, k ; p^{\prime}, p \leq P \\
N\left(1-N S_{p}\right) \quad \forall p ; p \leq P
\end{gathered}
$$

Objective function (1) minimises the total manufacturing cost consisting of the production cost, cost of scrap, CIs fixed and variable costs, MIs fixed and variable costs, fixed cost of inspection stages and warranty cost, respectively. Equations (2) and (3) ensure that the inspection of a quality characteristic for all parts be performed just in one inspection stage. Equation (4) implements the MI-or-CI strategy in the model and allocates one kind of inspection strategy for each quality characteristic. Equation (5) makes a connection between an operationlprimes failure rate and the decision that whether the MI has been considered for that characteristic or not. Constraints (6) and (7) calculate the amount of scrap based on error type I and II after each inspection stage. Constraints (8) and (9) determine the in-process parts after each operation. Because of scrap detection and removal, the number of parts can decrease in the presence of any inspection. Equations (10) and (11) calculate the total number of MIs and CIs after operations. Constraint (12) calculates different inspection stages among the whole process. Moreover, constraints (13) to (37) are provided to linearise the nonlinear terms. Finally, constraints (38) and (39) are positivity and integer constraints.

\subsubsection{Formulation of MI-and-CI strategy}

This section provides the mathematical modelling for the second inspection strategy in which none, one or both MI and $\mathrm{CI}$ can be performed for each quality characteristic. The mathematical model for the second strategy is as follows: 


$$
\begin{aligned}
\min O F V_{D}= & \sum_{p=1}^{P} p c_{p} N_{p}+\sum_{p=1}^{P} s c_{p} S c r a p_{p}+\sum_{p=1}^{P} \sum_{k=1}^{K} f c_{p k} N C I S_{p k}+\sum_{p=1}^{P} \sum_{k=1}^{K} c f_{k} V C_{p k} N X C_{p}+\sum_{p=1}^{P} \sum_{k=1}^{K} f m_{p k} N M I S_{p k} \\
& +\sum_{p=1}^{P} \sum_{k=1}^{K} m f_{k} V M_{p k} N X M_{p}+\sum_{p=1}^{P} f_{S_{p}} N S N_{p}+\sum_{p=1}^{P} \sum_{k=1}^{K} w c_{k}\left(R C I_{p k} \beta_{p k}+R M I_{p k}\right)
\end{aligned}
$$

s.t: (2), (3), (5)-(39).

$$
C I_{p^{\prime} k}+M I_{p^{\prime} k} \leq 2 b_{p^{\prime} k} \quad \forall p^{\prime}, k
$$

\section{Robust optimisation}

In addition to the numerous concerns of manufacturers regarding the inspection planning, lack of information about production processes and several environmental factors has imposed a degree of uncertainty to the design parameters which directly affect other decisions of production (Galbraith 1973; Ho 1989). However, in all industries, quality of products is decreased as a result of manufacturing variations such as performance degradation, nonconformance to specifications, high cost of redesign or scrap and failure; classical methods consider deterministic conditions during the design of the process, while the manufacturing processes are generally stochastic. Consequently, some of the manufactured products do not conform to design specifications and their processes are sensitive to manufacturing variations. Traditionally, tight tolerance or higher precision in the manufacturing process was applied to solve this issue, which leads to noticeable manufacturing cost. Hence, manufacturers are interested in less sensitive manufacturing processes by taking into account the effect of manufacturing variations on the products during the design phase. These manufacturing processes are robust processes which are relatively insensitive to alteration of uncertain parameters. It is noteworthy that in the robust manufacturing processes, the effect of uncertainty in the system is minimised without eliminating the sources of uncertainty.

One of the most important effects of production variations and uncertainty in any industry is increasing the number and cost of scraps. Scrap cost is a manufacturing reality affecting organisations across all industries and product lines. No matter why scrap occurs, its impacts on an organisation are always wasted time and money, while no organisation wants to admit it, these expenses add up quickly and negatively impact the bottom line. Although it is near impossible to eliminate scrap completely, managers can reduce the amount of scrap in their organisation by optimising the way they produce the products. Therefore, manufacturers can help reduce scrap by carefully and consistently monitoring the parameters of the process to know how products are made. As a consequence of this monitoring, parameters with higher variation are being controlled and the number of scraps is decreased.

Since one of the main resources of variation in the production process is the misadjustment of an operation, designing an inspection planning that is less sensitive to the misadjustment is expected. According to Figure 1, misadjustment of an operation has a direct impact on the failure rate and the amount of scraps. In fact, the higher the value of misadjustment is, the higher the value of failure rate and the amount of scraps are. Besides, the failure rate of each operation is one of the most significant parameters that affects the quality of the products. Therefore, in this study, the alteration of operations' failure rate is taken into account to design a robust inspection plan.

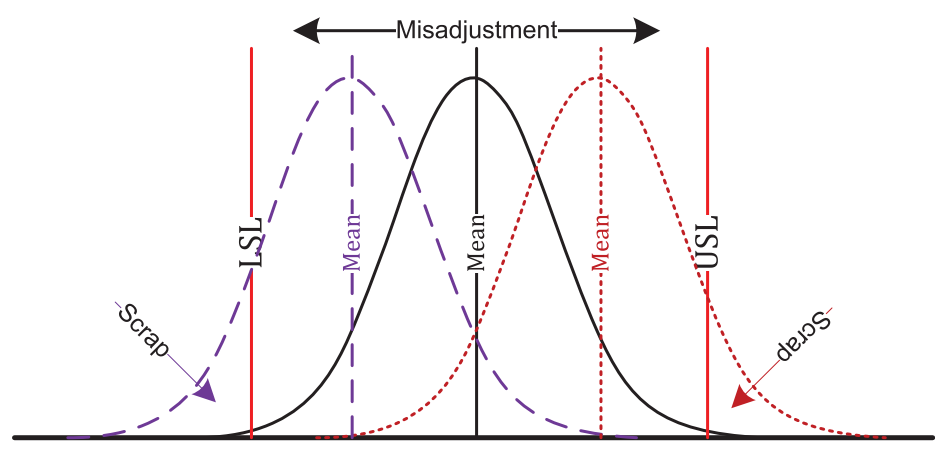

Figure 1. Effect of misadjustment on failure rate. 
In the following, it will be shown that how failure rate variations indirectly affect the objective function of the proposed model. The objective of the proposed mathematical model is to minimise the total cost which is the sum of the manufacturing (i.e. production cost + inspection cost) and the warranty costs. According to the objective function (1), the first seven terms of $O F V_{D}$ represent the manufacturing cost and the last term denotes the warranty cost. It can easily be proved that these two parts of the objective function are in contrast in terms of the number of conformity inspections $(N C)$, where having higher $N C$ increases the manufacturing cost and at the same time decreases the warranty cost. This directly relates to the amount of scraps, where considering CIs in the process increases the cost of inspections (i.e. third and fourth terms of the objective function) but decreases the warranty cost. Hence, uncertainty in the failure rate, which directly affects the amount of scraps, makes tangible changes in the objective function.

In order to investigate the effect of failure rate in the result of the proposed model, the pseudo-trade-off diagram of manufacturing and warranty costs is illustrated in Figures 2-4. Vertical and horizontal axes show cost and $N C$, respectively. Figure 2 demonstrates the trade-off diagram for deterministic problem, in which no alteration in the parameters has been considered. Since, in the deterministic problem, the increase rate of the manufacturing cost is more than the decrease rate of the warranty cost; therefore, the minimum total cost belongs to a solution with no conformity inspection (i.e. $N C=0$ ). It is obvious that alteration in failure rate significantly affects the amount of scraps as well as the value of warranty cost. Figure 3 depicts the trade-off cost diagram for a problem with little increase in misadjustment which consequently increases the failure rate. As it can be seen, the decrease rate of warranty cost is initially more than the increase rate of the manufacturing cost for $N C \leq N_{2}^{*}$ and vice versa for $>N_{2}^{*}$. Therefore, the minimum total cost occurs for a solution with $=N_{2}^{*}$. Similarly, Figure 4 illustrates the trade-off cost diagram for a problem with higher increases in misadjustment compared to the problem in Figure 3. The optimal $N C$ in the problem with higher uncertainty in misadjustment is equal to $N_{3}^{*}$. It can also be inferred from Figures 3 and 4 that the higher the uncertainty in the misadjustment, the higher the $N C$ is (i.e. $N_{3}^{*}>N_{2}^{*}$ ). It should be noted that Figures 2-4 have been conceptually illustrated based on the proposed mathematical model; however, the curve of manufacturing and warranty cost is not so simple in the industries, while the general results and trends are similar. For better supporting the effect of failure rate's uncertainty, several experiments have been done in Section 6.

Several methods have been proposed to take manufacturing variations and uncertainty in input parameter into account in order to design a robust manufacturing process (Arvidsson and Gremyr 2008; Beiqing and Du 2006; Gyung-Jin and Lee 2002; Hans-Georg and Sendho 2007; Michael 1996; Torben, Arvidsson, and Gremyr 2009; Wei et al. 1996; Xiaoping and Chen 2000). In this study, we apply a special case of Taguchi's method (Jin and Sendhoff 2003) to cope with the uncertainty of the misadjustment and in order to design a robust inspection process plan. Robustness of an optimal solution can usually be discussed from the following two perspectives:

- The optimal solution is insensitive to any variations of the design variables.

- The optimal solution is insensitive to any variations of the environmental parameters.

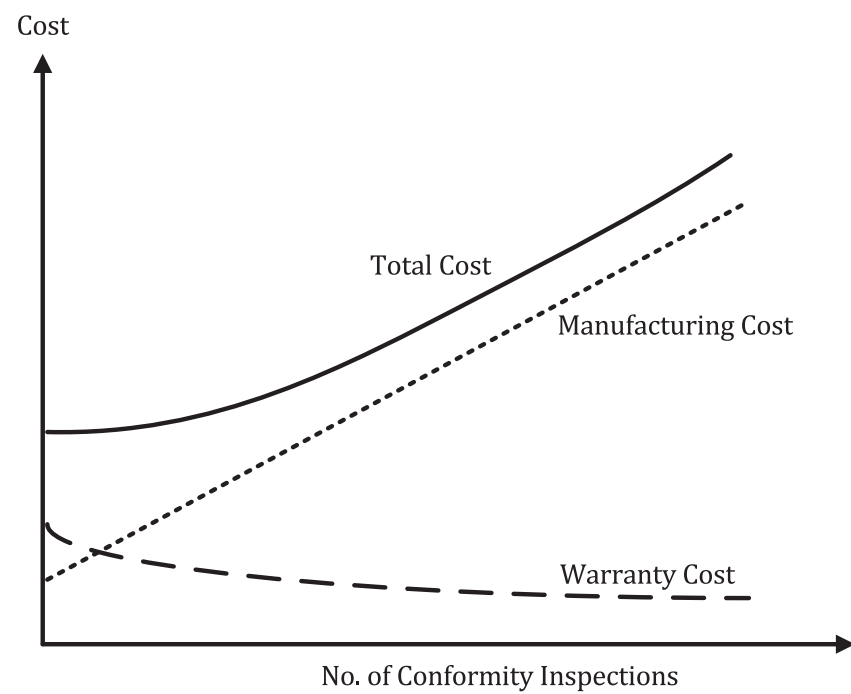

Figure 2. Deterministic trade-off cost diagram. 


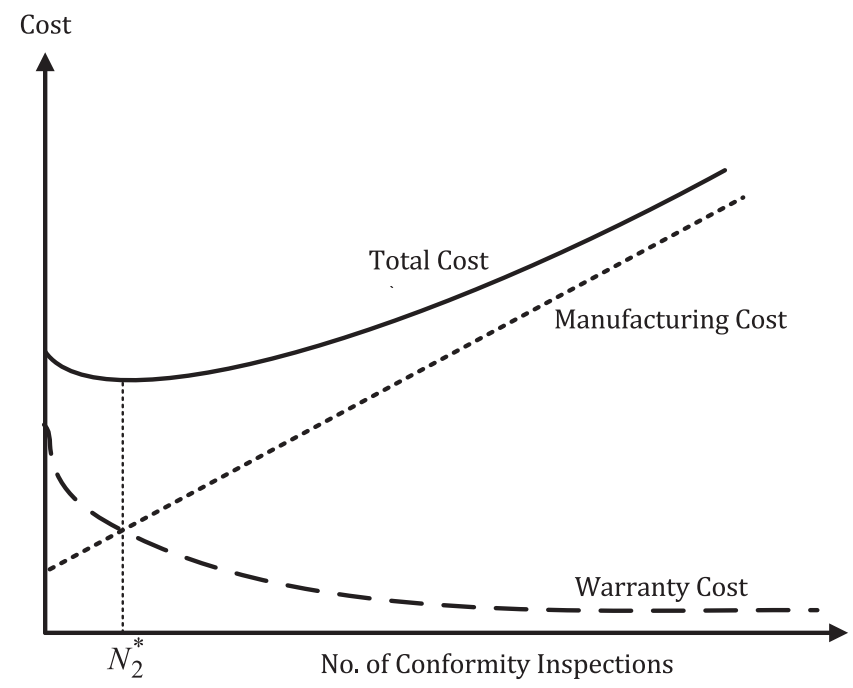

Figure 3. Trade-off cost diagram with lower uncertainty.

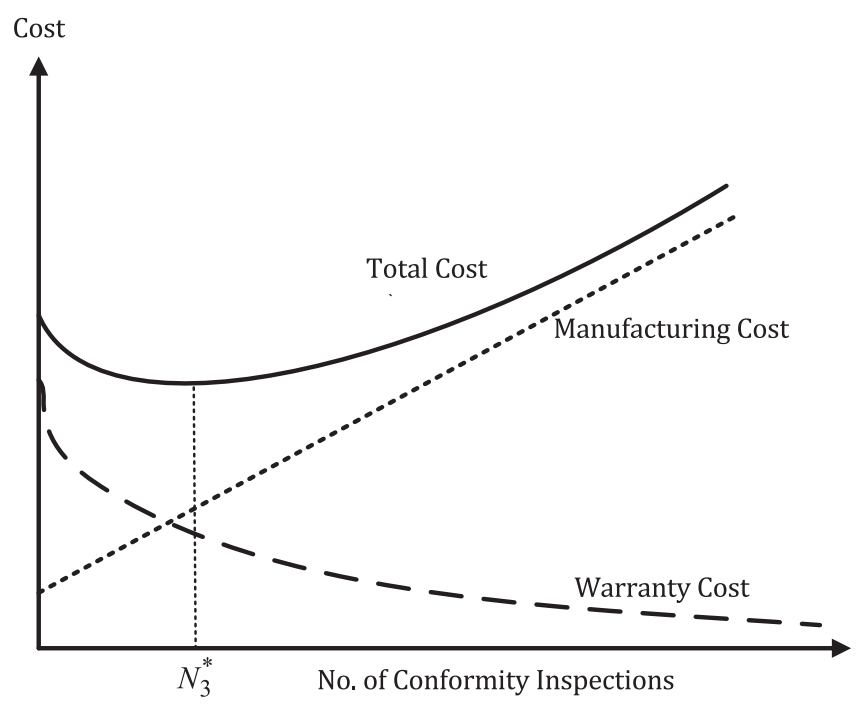

Figure 4. Trade-off cost diagram with higher uncertainty.

In order to increase the robustness of the solutions, two methods have been mostly used as follows (Beyer, Olhofer, and Sendhoff 2002; Das 2000):

- Optimisation of the expected value of the objective function under different alteration in the uncertain input parameters.

- Minimisation of the objective function variance under different alteration in the uncertain input parameters.

It has been mentioned that although the expectation-based measure does not sufficiently take care of variations of the objective function, these variations are symmetric around the average value; on the other hand, a purely variancebased measure also does not take the absolute value of the solution into account. Hence, we formulate a single objective optimisation problem which minimises both expected value and variance of the objective function to search for robust optimal solutions. For this purpose, two different combinations of expected and variance values, namely Taguchi methods 1 and 2 (i.e. T1 and T2), are considered as in Equations (41) and (42) that must be minimised (Gyung-Jin et al. 2006). First, necessary notations are provided as below. 
Parameters:

MCR Number of Monte Carlo runs

$\omega \quad$ Weight factor of standard deviation in Taguchi method

$C P_{p} \quad$ Process capability. A simple and straightforward indicator of process capability

$C P k_{p} \quad$ Process capability Index. Adjustment of $C P$ for the effect of noncentred distribution

Variables:

$\mu_{\text {cost }} \quad$ Cost mean value

$\sigma_{\text {cost }} \quad$ Cost standard deviation value

$O F V_{T 1} \quad$ Objective function value of Taguchi method 1

$O F V_{T 2} \quad$ Objective function value of Taguchi method 2

$$
\begin{gathered}
O F V_{T 1}=\mu_{\text {Cost }}+\omega \sigma_{\text {Cost }} \\
O F V_{T 2}=\left(\mu_{\text {Cost }}-O F V_{D}\right)^{2}+\omega \sigma_{\text {Cost }}^{2}
\end{gathered}
$$

The purpose of the objective function in Equation (41) is merely to minimise variation through expected value and standard deviation; while the objective function in Equation (42) not only tries to reduce variation through expected value and standard deviation, but also attempts to shift the mean value to a target value (i.e. deterministic value).

Now, we first need to vary the misadjustment in its variation interval then calculate the expected and standard deviation values through different variations. This procedure is repeated for each solution. Finally, a solution with the minimum value of objective functions (41) or (42) would be the most robust one.

To generate different values for misadjustment, a Monte Carlo simulation technique is utilised. In order to generate random values of misadjustment, it must be regarded that the quality characteristic $k$ of operation $p$ needs monitoring or conformity inspection. Based on the type of inspection, the failure rate in the presence of monitoring $\left(F R_{p k}^{M I}\right)$ and conformity $\left(F R_{p k}^{C I}\right)$ inspections is calculated as Equations (43) and (44) (Kane 1986).

$$
\begin{gathered}
F R_{p k}^{M I}=1-P\left\{z \leq 3 \times C P_{p}-r_{M I}\right\}+P\left\{z \leq-3 \times C P_{p}-r_{M I}\right\} \\
F R_{p k}^{C I}=1-P\left\{z \leq 3 \times C P k_{p}-r_{C I}\right\}+P\left\{z \leq-3 \times C P k_{p}-r_{C I}\right\}
\end{gathered}
$$

where $r_{M I}$ and $r_{C I}$ are uniformly generated from $[0,1]$ and $[0,2]$ intervals, respectively. It should be noted that these intervals are provided by experts. Accordingly, the flowchart of $\mathrm{T} 1$ and $\mathrm{T} 2$ robust methods are as Figures 5 and 6 , respectively.

\section{Proposed solution algorithm}

In order to solve the proposed process inspection plan with stochastic complexity, the solution algorithm must be capable of obtaining the optimal or near-optimal solution within the reasonable time. There are several methods in the literature such as simplex and dynamic programming-based optimisation algorithms for providing an optimal solution for small-size problems (Shukla, Tiwari, and Ceglarek 2013; Taha 2006). However, most of the real-world problems have large sizes and solving them by mathematical programming approaches takes considerable computational time. Therefore, to cope with this challenging issue, a well-known evolutionary algorithm, namely genetic algorithm (GA), is utilised to solve the proposed process inspection planning. It has been shown that evolutionary algorithms such as genetic algorithms (Holland 1975) or evolution strategies (Back, Hoffmeister, and Schwefel 1991) are efficient and robust approaches to solve a wide range of optimisation problems. Application of these algorithms in the area of inspection planning and allocation can be found in Hanne and Nickel (2005), Shiau (2003b), Alam et al. (2003) and Shiau, Lin, and Chuang (2007).

GA is an algorithm inspired by natural evolution to solve optimisation problems (Goldberg 1989; Holland 1975). Each solution of a given problem is represented in the form of a string, called chromosome, which is a combination of several genes that hold a set of information about the problem (Goldberg 1989). GA starts with a randomly generated 


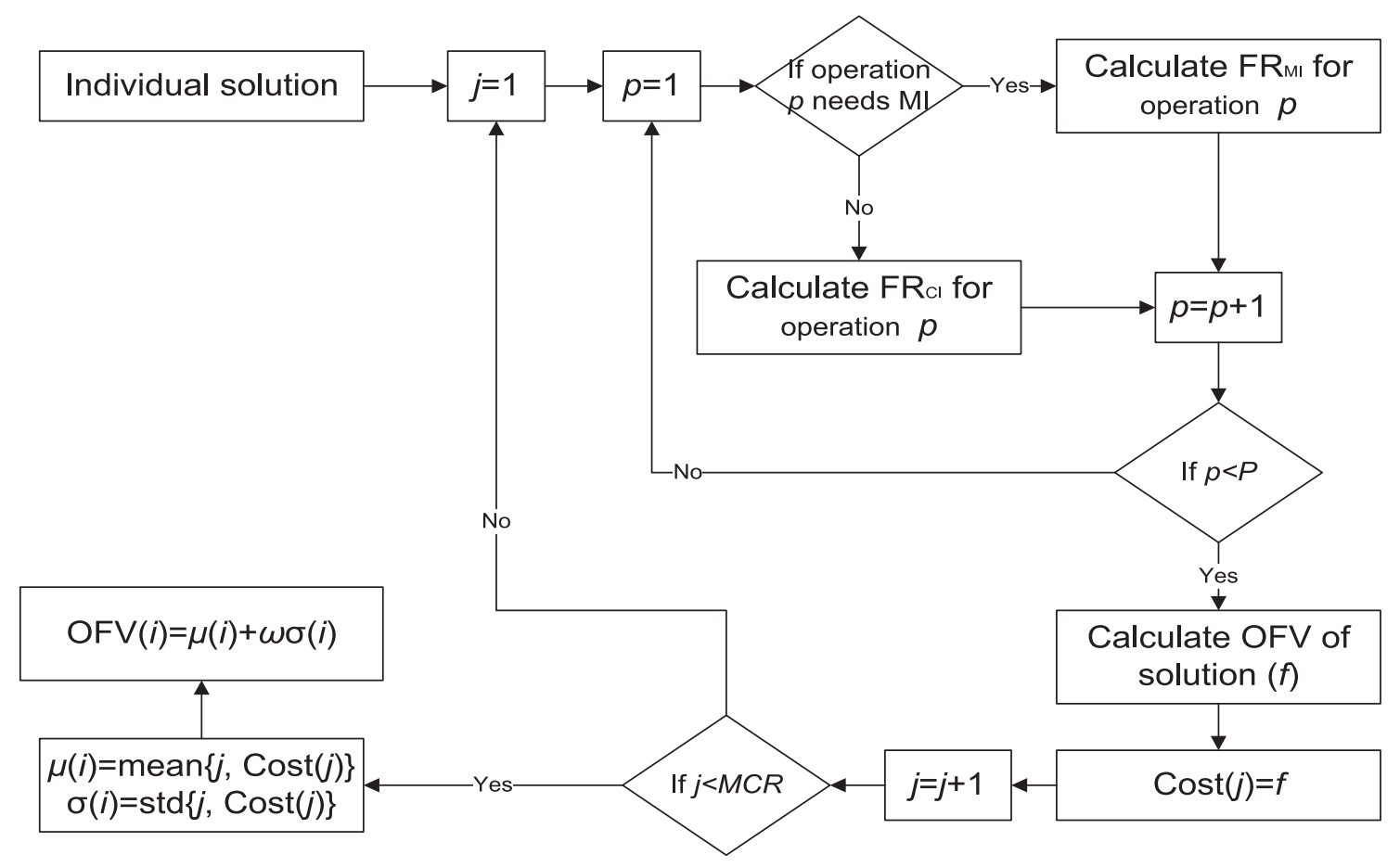

Figure 5. Flowchart of the T1 method.

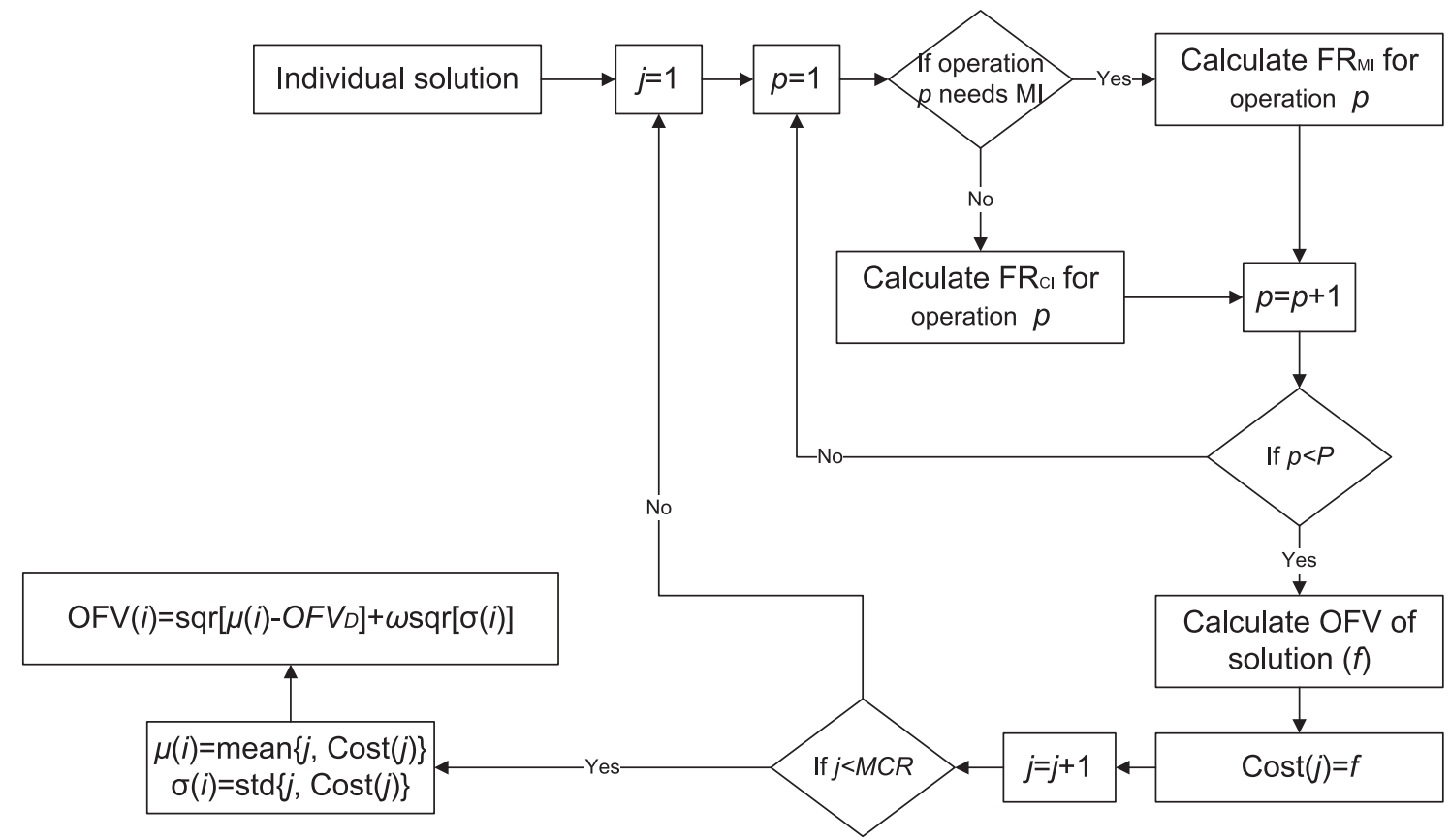

Figure 6. Flowchart of the T2 method.

population of individual solutions (i.e. chromosomes). The fitness of each chromosome reflects the value of the objective function. To find better solutions (offspring), best chromosomes share their information through crossover and mutation operators. The new created solutions are then evaluated and are used to create a new generation if they provide better fitness. This process is repeated fore given number of iterations to obtain the best individual. 
Each chromosome of the proposed process inspection planning problem must contain information about which-what and when decisions. For this aim, a new solution representation is developed which includes two different parts representing (1) which-what and (2) when decisions. For example, consider a problem with 6 quality characteristics with which-what and when decisions as shown in Figures 7 and 8, respectively.

In Figure 7, each column represents a quality characteristic. Moreover, at each column, value 1 at the first row means that the related quality characteristic needs monitoring inspection and value 1 in the second row indicates the need for conformity inspection. Accordingly, in Figure 7, quality characteristics number 1, 2 and 4 need CI, quality, characteristic number 3 needs both MI and CI and quality characteristic number 5 and 6 need MI. In Figure 8, the columns explain the operations and the rows signify the quality characteristics. Therefore, value 1 at each array indicates that the inspection of related characteristic (i.e. the row number of an array) is performed after the determined process (i.e. the column number of an array). For instance, MI for characteristic numbers 3, 5 and 6 is carried out after operation number 3, 6 and 6, respectively. Besides, CI of characteristic number 1, 2, 3 and 4 is carried out after operation number $3,6,6$ and 6 , respectively.

\section{Experimental results}

In this section, in order to validate the correctness and performance of the proposed mathematical model and solution algorithm, the model is applied on an industrial case related to a part with 15 quality characteristics. The presented GA is coded in MATLAB environment and runs using a computer with Intel Pentium 4, $2.3 \mathrm{GHz}$ CPU and 4GBof RAM.

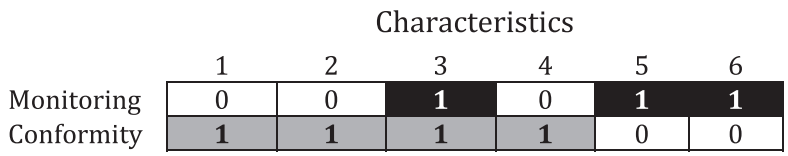

Figure 7. Which-what decision.

\begin{tabular}{|c|c|c|c|c|c|c|}
\hline & \multicolumn{6}{|c|}{ Operations } \\
\hline & 1 & 2 & 3 & 4 & 5 & 6 \\
\hline \multirow{6}{*}{ 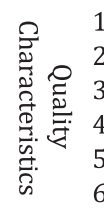 } & 0 & 0 & 1 & 0 & 0 & 0 \\
\hline & 0 & 0 & 0 & 0 & 0 & 1 \\
\hline & 0 & 0 & 1 & 0 & 0 & 1 \\
\hline & 0 & 0 & 0 & 0 & 0 & 1 \\
\hline & 0 & 0 & 0 & 0 & 0 & 1 \\
\hline & 0 & 0 & 0 & 0 & 0 & 1 \\
\hline
\end{tabular}

Figure 8. When decision.

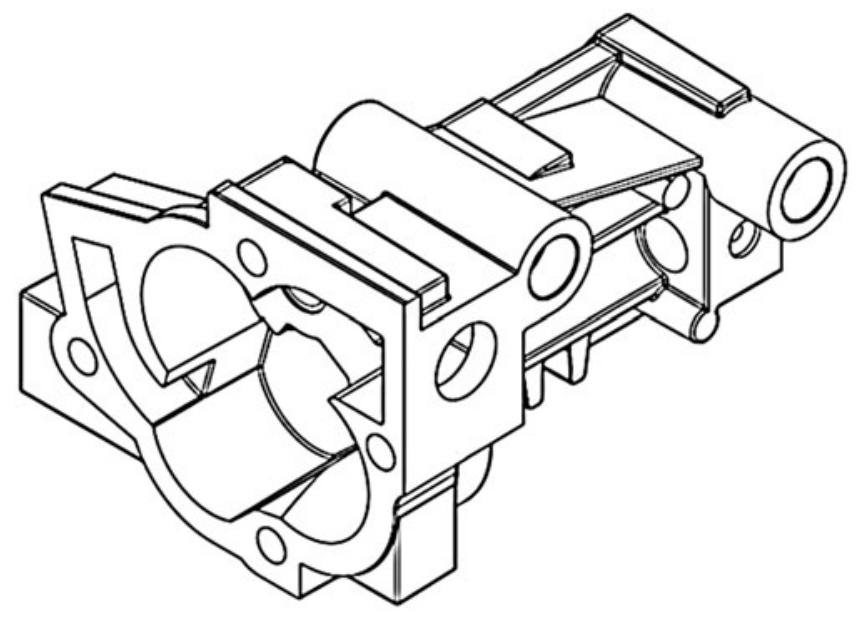

Figure 9. Solid frame of the industrial part. 
First, some information about the industrial case such as production time, process capabilities, failure rate and allowable places to perform an inspection for each quality characteristic is presented. Then, the results of the model for the industrial case are provided.

A crucial part in a car manufacturing company with 15 different quality characteristics has been selected for our case. Figures 9 and 10 demonstrate the solid frame of the part and labelled quality characteristics which need to be inspected. Some required deterministic information (i.e. without misadjustment) about the industrial case is listed in Table 1, in which first to seventh columns explain the number of the operations; name of the operation; the production time; process capability $C_{p}$ and $C_{p k}$ and failure rates with and without monitoring inspection. Besides, the allowable places (AP) that inspections (i.e. CI and MI) of each quality characteristic can be performed are listed in the last

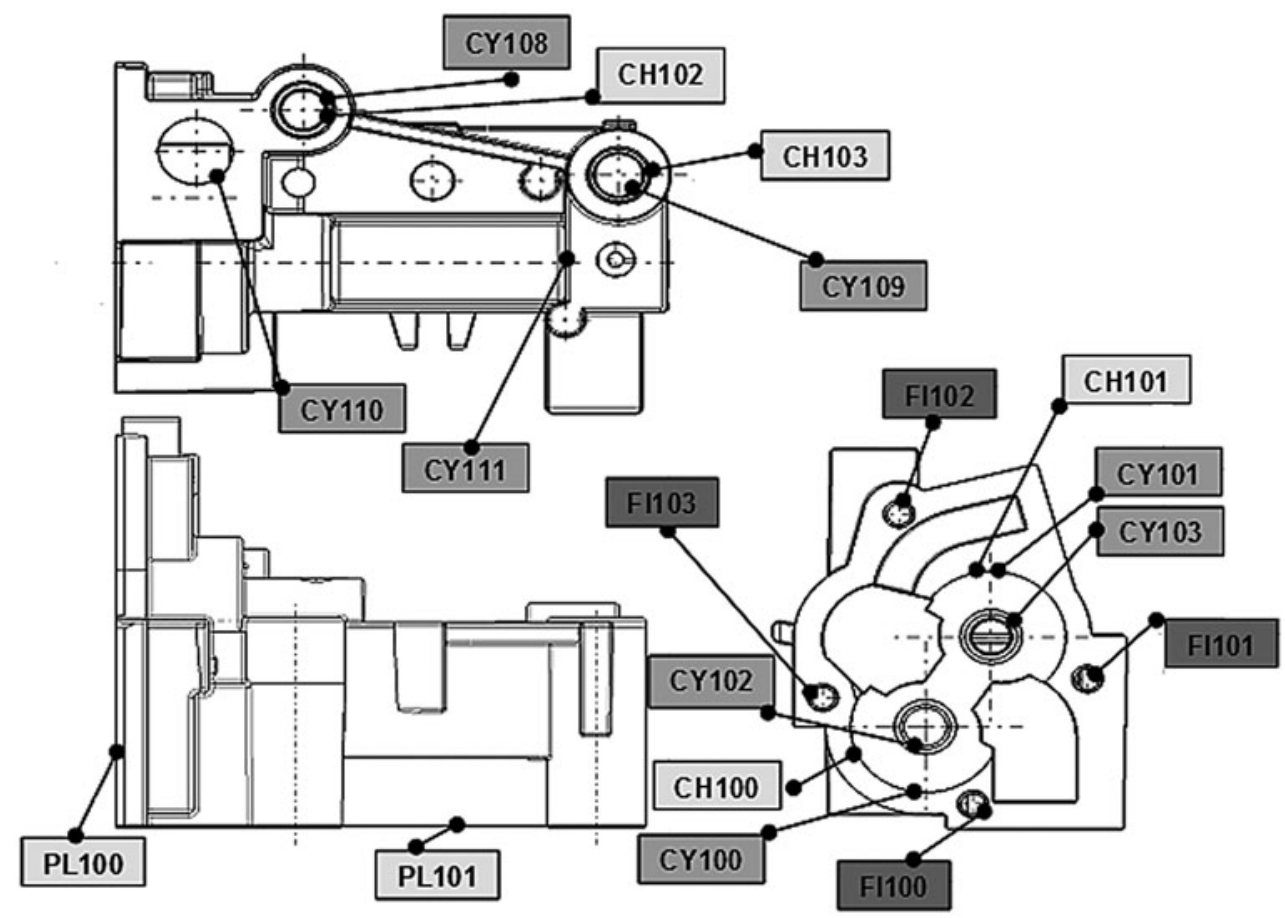

Figure 10. Labelled operations of the industrial part.

Table 1. Information about the industrial case.

\begin{tabular}{|c|c|c|c|c|c|c|c|}
\hline \multirow[b]{2}{*}{ Operation number } & \multirow[b]{2}{*}{ Operation name } & \multicolumn{6}{|c|}{ Details } \\
\hline & & $P T$ & $C_{p}$ & $C_{p k}$ & $F R^{1}$ & $F R^{2}$ & $A P$ \\
\hline 1 & Rough milling PL100 & 0.148 & 2 & 1.50 & $1.97 \mathrm{e}-9$ & $6.79 \mathrm{e}-6$ & $1 \rightarrow 13$ \\
\hline 2 & Rough milling PL100 & 0.166 & 2 & 1.50 & $1.97 \mathrm{e}-9$ & $6.79 \mathrm{e}-6$ & $2 \rightarrow 14$ \\
\hline 3 & Rough milling PL101 & 0.133 & 2 & 1.66 & $1.97 \mathrm{e}-9$ & $6.35 \mathrm{e}-7$ & $3 \rightarrow 15$ \\
\hline 4 & Boring CY110 & 0.154 & 1.60 & 1.33 & $1.58 \mathrm{e}-6$ & $6.60 \mathrm{e}-5$ & $4 \rightarrow 10$ \\
\hline 5 & Rough drilling CY108 \& CY109 & 0.09 & 2 & 1.66 & $1.97 \mathrm{e}-9$ & $6.35 \mathrm{e}-7$ & $5 \rightarrow 10$ \\
\hline 6 & Chamfering CY108 \& CY109 & 0.25 & 2 & 1.66 & $1.97 \mathrm{e}-9$ & $6.35 \mathrm{e}-7$ & $6 \rightarrow 6$ \\
\hline 7 & Chamfering CY100 \& CY101 & 0.257 & 1.50 & 1.20 & $6.79 \mathrm{e}-6$ & $3.18 \mathrm{e}-4$ & $7 \rightarrow 15$ \\
\hline 8 & Boring CY100 & 0.257 & 1.50 & 1.20 & $6.79 \mathrm{e}-6$ & $3.18 \mathrm{e}-4$ & $8 \rightarrow 15$ \\
\hline 9 & Boring CY101 & 0.122 & 1.66 & 1.30 & $6.35 \mathrm{e}-7$ & $9.61 \mathrm{e}-5$ & $9 \rightarrow 12$ \\
\hline 10 & Rough drilling CY102 \& CY103 & 0.109 & 1.66 & 1.40 & $6.35 \mathrm{e}-7$ & $2.66 \mathrm{e}-5$ & $10 \rightarrow 12$ \\
\hline 11 & Rough drilling CY111 & 0.134 & 1.66 & 1.40 & $6.35 \mathrm{e}-7$ & $2.66 \mathrm{e}-5$ & $11 \rightarrow 15$ \\
\hline 12 & Boring CY108 \& CY109 & 0.122 & 1.30 & 1.10 & $9.61 e-5$ & $9.66 \mathrm{e}-4$ & $12 \rightarrow 15$ \\
\hline 13 & Boring CY102 \& CY103 & 0.122 & 1.30 & 1 & $9.61 e-5$ & $2.69 e-3$ & $13 \rightarrow 15$ \\
\hline 14 & Boring CY111 & 0.117 & 1.66 & 1.33 & $6.35 e-7$ & $6.60 e-5$ & $14 \rightarrow 15$ \\
\hline 15 & Finish milling PL100 & 0.129 & 1.66 & 1.33 & $6.35 \mathrm{e}-7$ & $6.60 \mathrm{e}-5$ & $15 \rightarrow 15$ \\
\hline
\end{tabular}


column. For instance, for the characteristic number 4 which belongs to the operation number 4 , MI or CI can be performed at any place after the operation number 4 to 10 and not further.

First of all, the effect of misadjustment's uncertainty on the objective function is investigated for both inspection strategies as Figure 11. Vertical and horizontal axes represent per cent of increase in total cost and values of misadjustment, respectively. The percentages of vertical axis have been calculated in comparison with deterministic value of the problem. In horizontal axis, for instance, misadjustment value equal to 2 means that the expected value $(E V)$ of the process varies upon $[E V-2 \sigma, E V+2 \sigma]$, where $\sigma$ is the dispersion of the process. It can be seen that by increasing the value of misadjustment, total cost of both strategies is extremely increased. In addition, the final inspection plan is also changed. It means that an optimal solution for deterministic problems may not be optimal any more for uncertain ones (see Figures 12-17).

In Figure 11, it can be seen that both inspection strategies are strongly sensitive to alteration of misadjustment. However, uncertainty in misadjustment leads to higher increase in cost in MI-and-CI strategy. It means that under MI-and-CI strategy, higher cost is required to make the inspection plan robust. Figures 12-14 illustrate the result of which-what and when decisions for deterministic (D) and T1 and T2 variants of the problem for MI-or-CI strategy. Similarly,

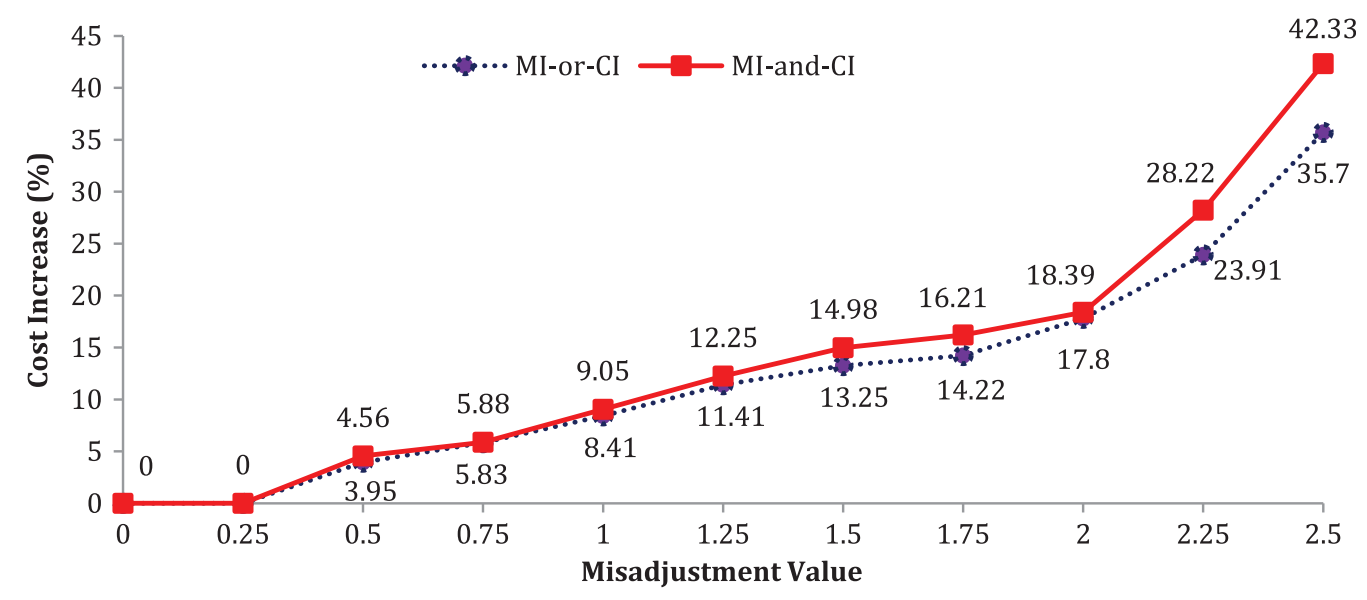

Figure 11. Percentage of cost increase versus misadjustment alteration.

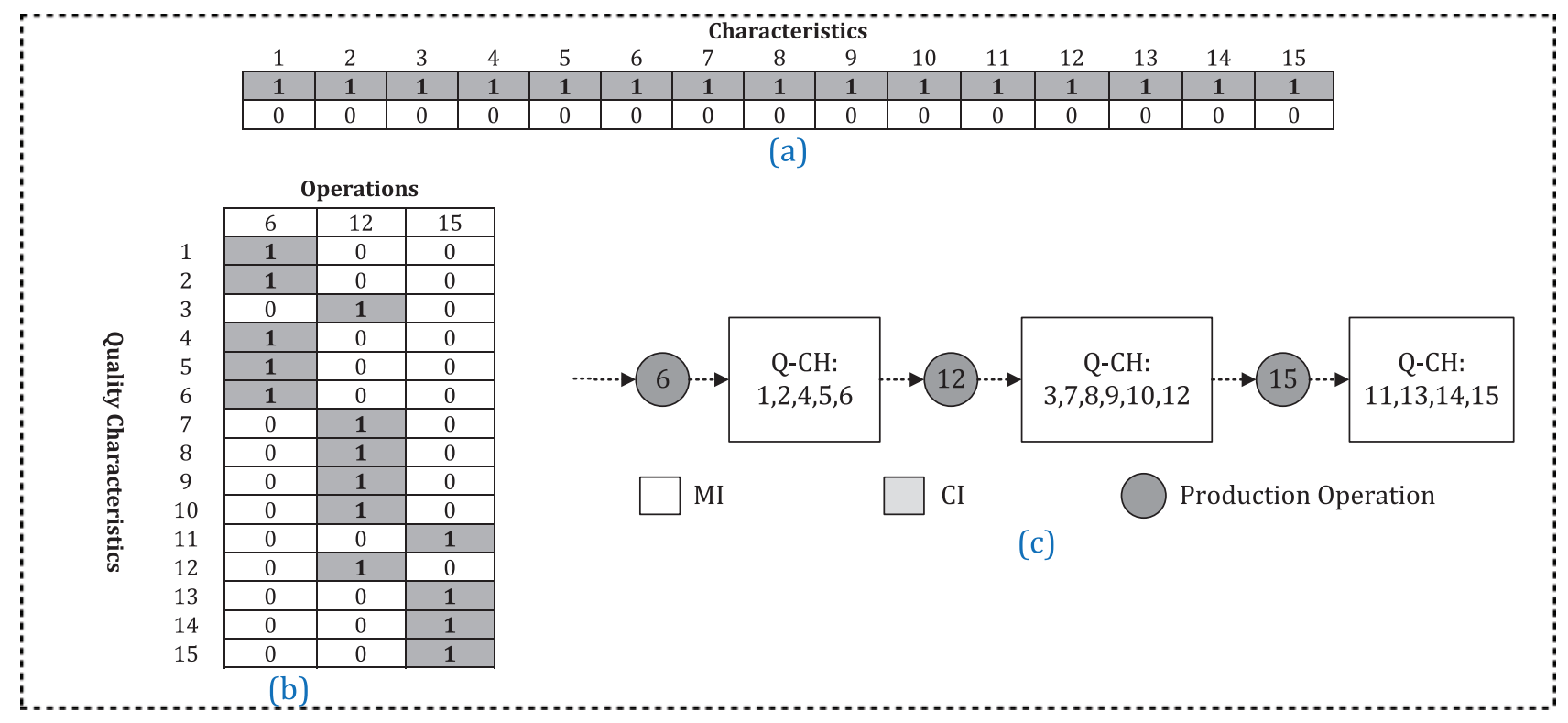

Figure 12. Deterministic result of the MI-or-CI strategy. 
Figures 15-17 illustrate the result of the which-what and when decisions for deterministic (D) and T1 and T2 variants of the problem for MI-and-CI strategy. Besides, part (c) of all Figures 12-17 illustrates scheme of the process and inspections. It is noteworthy that Figures $12-17$ also prove the pseudo-trade-off diagrams in Section 4. Finally, details of all the results have been presented in Table 2.

It can be seen from Figures 12 and 15 that not only no CI has been performed for all the quality characteristics, but also operations 2, 5 and 6 do not need MI under MI-and-CI strategy. Despite of the deterministic method, considering the uncertainty in the model causes CI to be performed for some of the quality characteristics. This study assumes that the minimum value of $\mu_{\text {Cost }}$ is $O F V_{D}$. Therefore, both T1 and T2 act similarly and obtain the same solution if and only if their objective functions are to minimise $\mu_{\text {Cost }}$ and $\left(\mu_{\text {Cost }}-O F V_{D}\right)$, respectively. On the other hand, considering

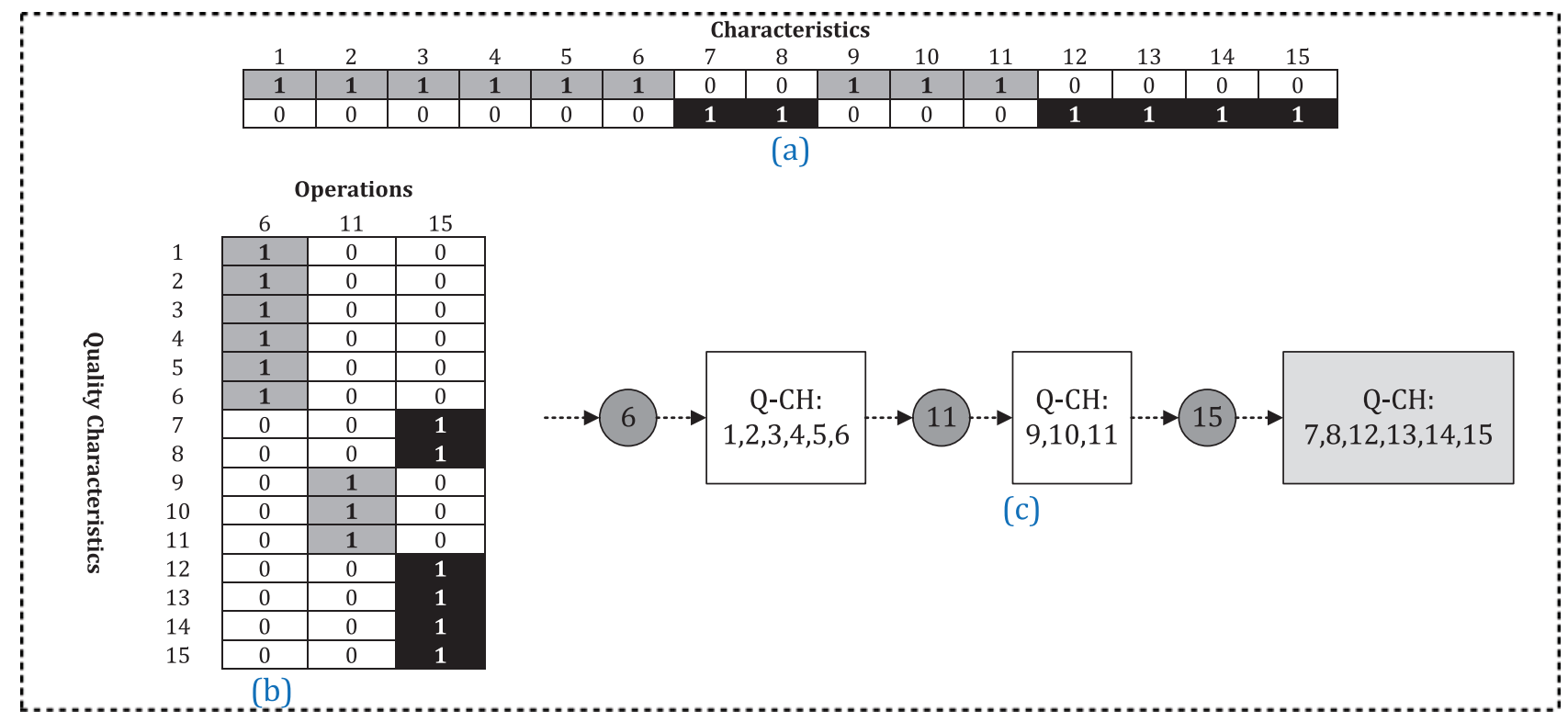

Figure 13. T1 result of the MI-or-CI strategy.

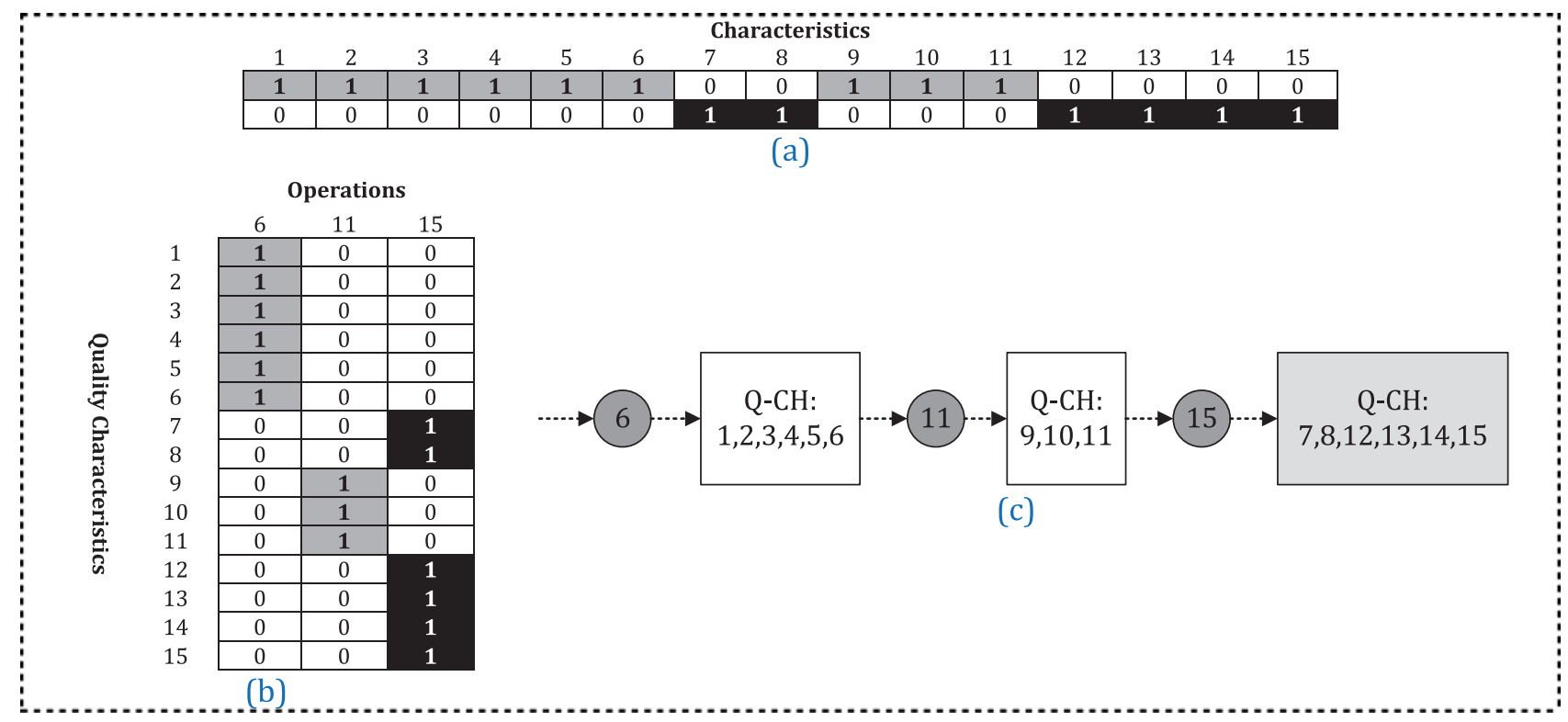

Figure 14. T2 result of the MI-or-CI strategy. 
standard deviation as well as the variance of the solutions in T1 and T2 makes a trade-off between manufacturing and warranty costs. It means that the lower the value of variation is, the lower the value of warranty cost is. Consequently, solutions with lower warranty cost are obtained by setting higher values of $\pi$.

In other words, increasing the value of $\pi$ decreases the value of warranty cost. However, in MI-or-CI strategy, the results of $\mathrm{T} 1$ and $\mathrm{T} 2$ are similar with $=0.4$. $\mathrm{T} 2$ has higher manufacturing and lower warranty costs comparing to $\mathrm{T} 1$ in MI-and-CI strategy. It can be explained that in T2 comparing to T1 in the same value of $\pi$, the term of minimising deviation in the objective function (i.e. $k \sigma_{\text {Cost }}^{2}$ ) relatively dominates the term of minimising mean cost (i.e. $\left.\left(\mu_{\text {Cost }}-O F V_{D}\right)^{2}\right)$. In addition, under MI-and-CI strategy, three sets of operations $\{2,5,6\},\{1,2,3,5,6\}$ and $\{1,2,3,6\}$ do not need any inspection for the deterministic T1 and T2 methods. According to Table 2, the objective function values of MI-or-CI strategy are more than those of MI-and-CI strategy for all the methods.

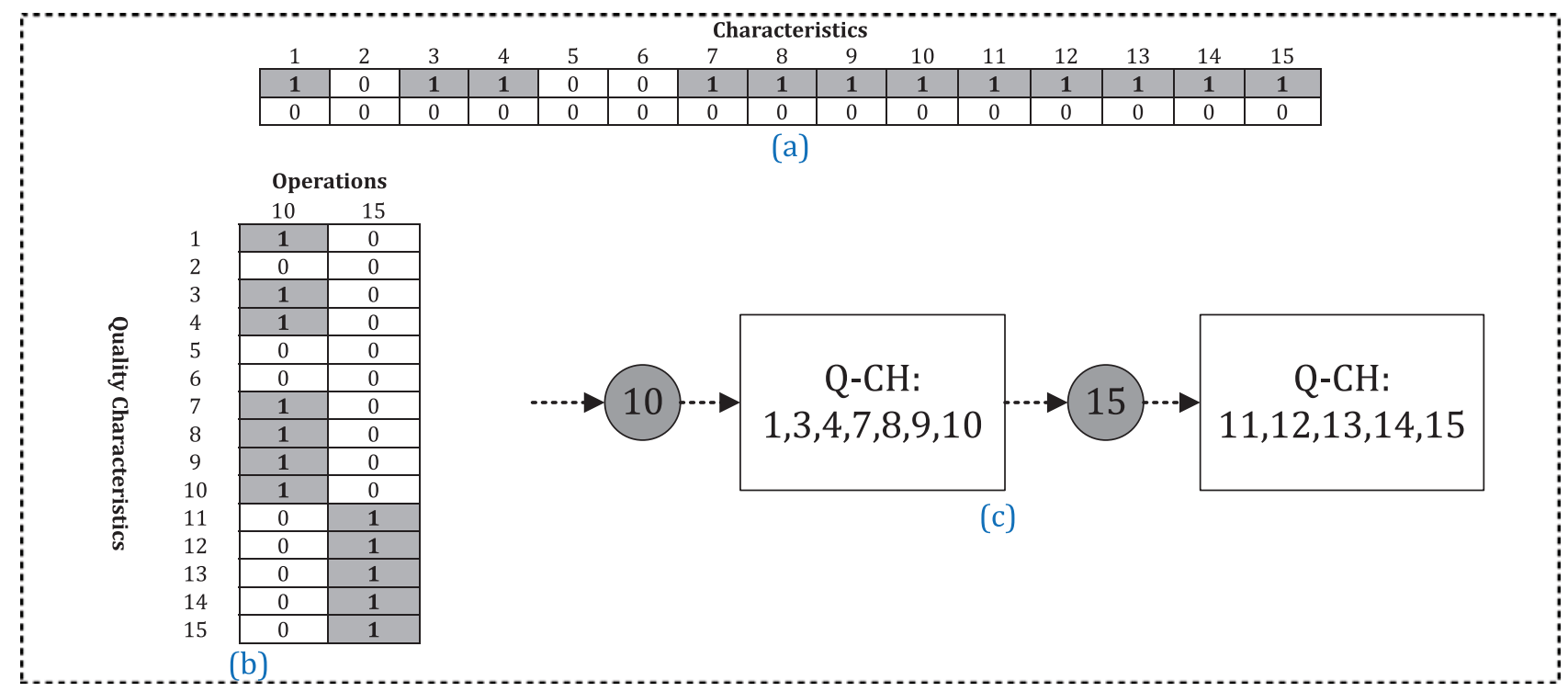

Figure 15. Deterministic result of the MI-and-CI strategy.

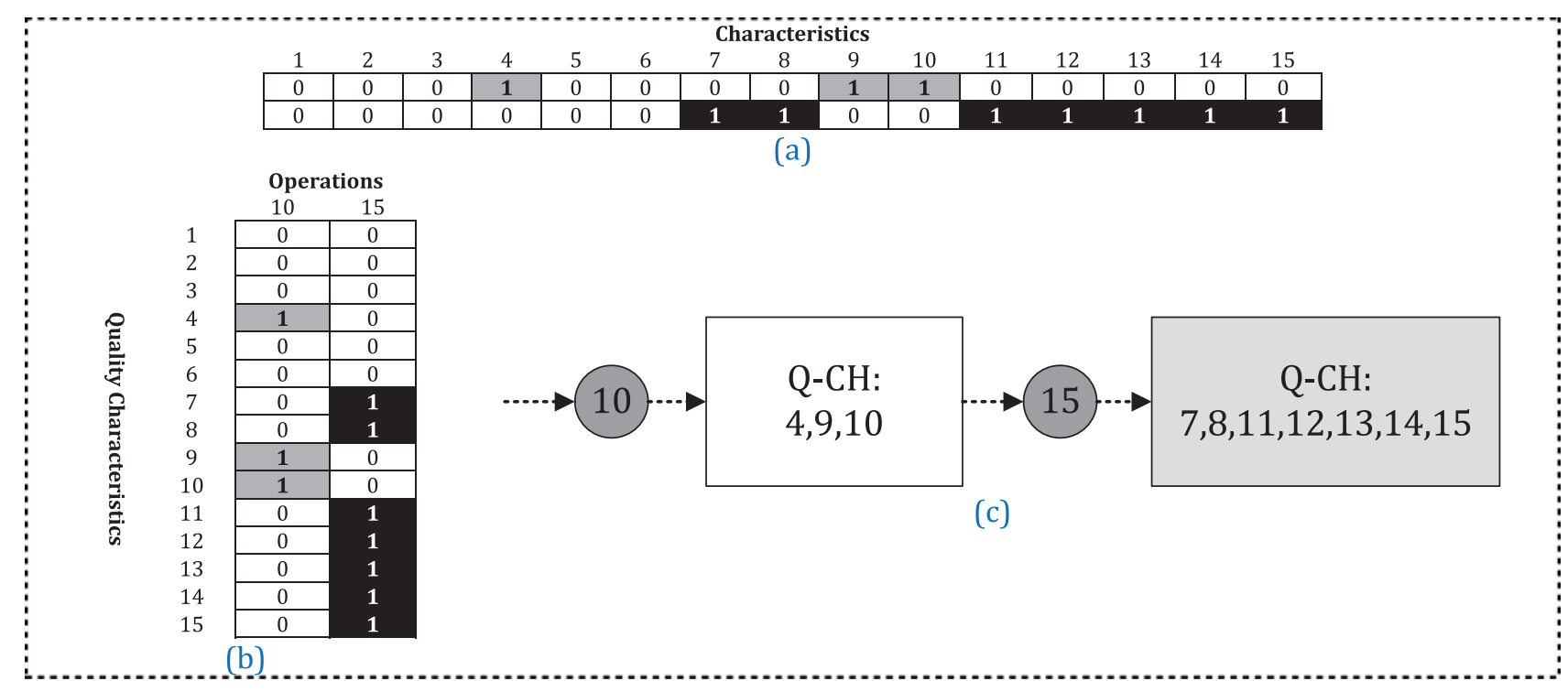

Figure 16. T1 result of the MI-and-CI strategy. 


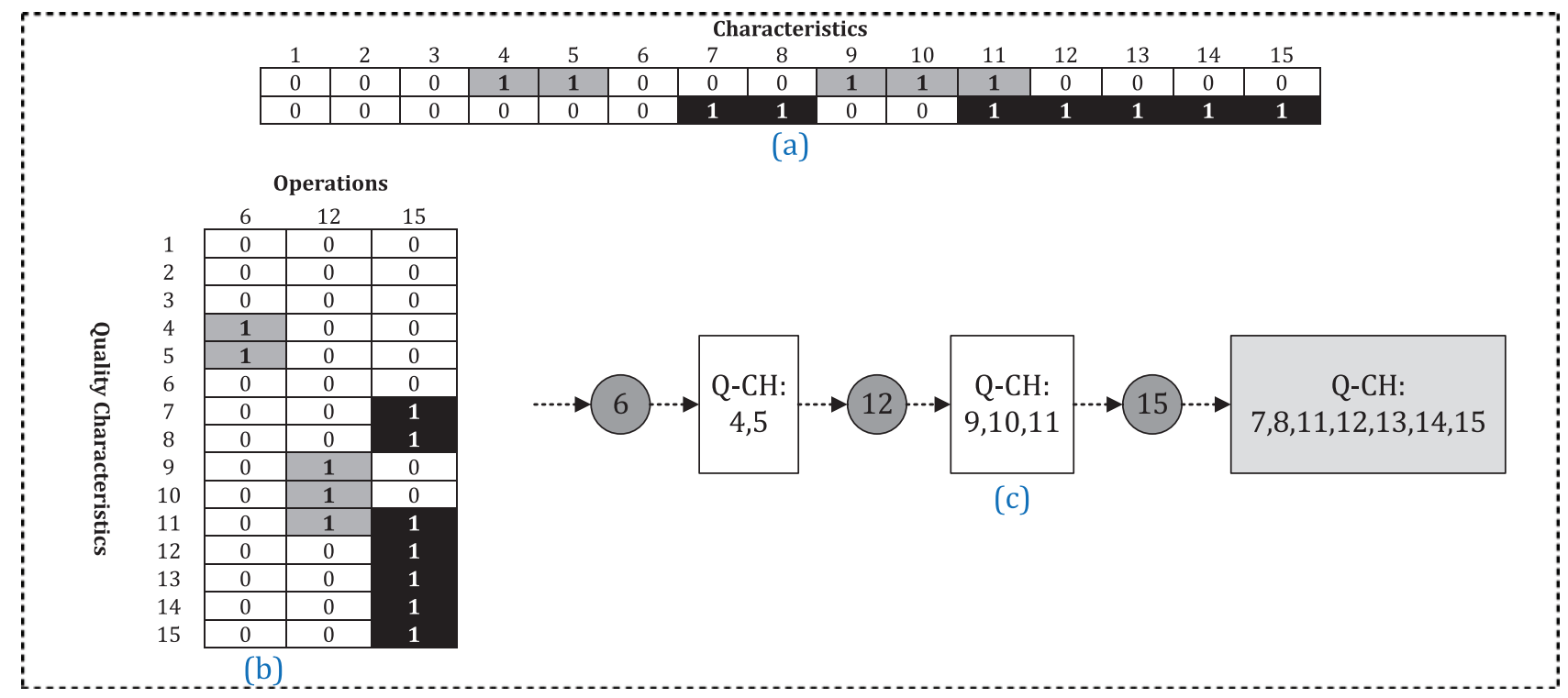

Figure 17. T2 result of the MI-and-CI strategy.

There are some characteristics which impose more variation to the objective function, and it can be proved that performing CI for them will reduce the variation (see Section 4). Regarding this proof, it can be easily conceived that $F R_{p k}^{M I}$ and $F R_{p k}^{C I}$ have an inverse relationship with $C P k_{p}$ and $C P_{p}$, respectively. Therefore, lowering the values of $C P k_{p}$ and $C P_{p}$ increases the values of $F R_{p k}^{M I}$ and $F R_{p k}^{C I}$, respectively. According to what we mentioned in Section 4, more numbers of $N C$ are needed once the failure rate of operations is increased. Since in the in-hand industrial case, the cost of the conformity inspection for all the operations is the same, an operation with the lowest value of $C P$ is selected and goes under conformity inspection, then, this selection is continued for the next lowest values of $C P S$ until the total cost reaches its global minimum. Since, the ascending order of $C P$ for the operations of the industrial case is like $C P_{12}=C P_{13}<C P_{7}=C P_{8}<C P_{4}=C P_{9}=C P_{10}=C P_{11}=C P_{14}=C P_{15}<C P_{1}=C P_{2}=C P_{3}=C P_{5}=C P_{6}$, the result of T1 method under MI-or-CI strategy contains 6 conformity inspections for operations 7, 8 and 12 to 15 . As a result,

Table 2. Details of cost objective function for the deterministic data.

\begin{tabular}{|c|c|c|c|c|c|c|c|c|c|}
\hline Method & Strategy & $\begin{array}{l}\text { Total } \\
\text { cost }\end{array}$ & $\begin{array}{l}\text { Production } \\
\text { cost }\end{array}$ & $\begin{array}{l}\text { Scrap } \\
\text { cost }\end{array}$ & $\begin{array}{c}\text { Fixed } \\
\text { conformity } \\
\text { cost }\end{array}$ & $\begin{array}{c}\text { Fixed } \\
\text { monitoring } \\
\text { cost }\end{array}$ & $\begin{array}{c}\text { Variable } \\
\text { conformity cost }\end{array}$ & $\begin{array}{c}\text { Variable } \\
\text { monitoring cost }\end{array}$ & $\begin{array}{c}\text { Warranty } \\
\text { cost }\end{array}$ \\
\hline $\mathrm{D}$ & MI-or- & 5160250 & 4812500 & 0 & 0 & 9000 & 0 & 314550 & 24200 \\
\hline $\mathrm{T} 1$ & CI & 6080603 & 4811774 & 2700 & 3600 & 5400 & 1045669 & 209700 & 1760 \\
\hline $\mathrm{T} 2$ & & 6080603 & 4811774 & 2700 & 3600 & 5400 & 1045669 & 209700 & 1760 \\
\hline $\mathrm{D}$ & MI-and- & 5068120 & 4812500 & 0 & 0 & 7200 & 0 & 209700 & 38720 \\
\hline T1 & CI & 6000253 & 4811774 & 2700 & 4200 & 1800 & 1045669 & 104850 & 29260 \\
\hline $\mathrm{T} 2$ & & 6104763 & 4811774 & 2700 & 4200 & 3000 & 1045669 & 209700 & 27720 \\
\hline
\end{tabular}

Table 3. Manufacturing cost versus warranty cost.

\begin{tabular}{llccr}
\hline Method & Strategy & Total cost & Manufacturing cost & Warranty cost \\
\hline D & MI-or-CI & 5160250 & 5136050 & 24200 \\
T1 & & 6080603 & 6078843 & 1760 \\
T2 & 6080603 & 6078843 & 1760 \\
D & MI-and-CI & 5068120 & 5029400 & 38720 \\
T1 & & 6000253 & 5970993 & 29260 \\
T2 & & 6104763 & 6077043 & 27720 \\
\hline
\end{tabular}




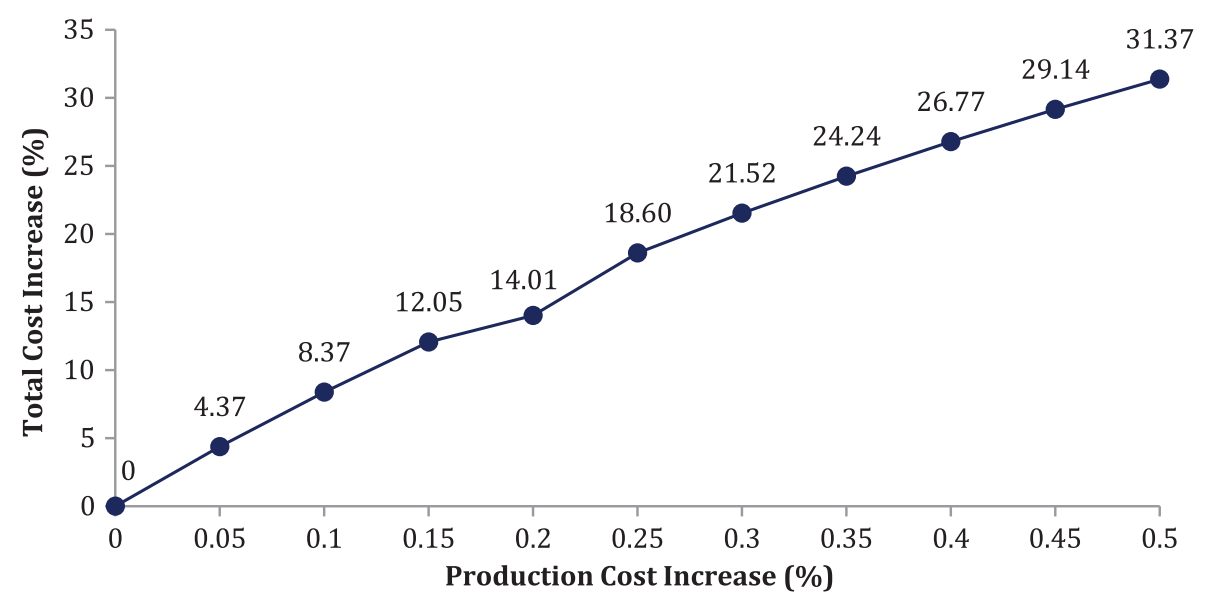

Figure 18. Impact of production cost on total cost.

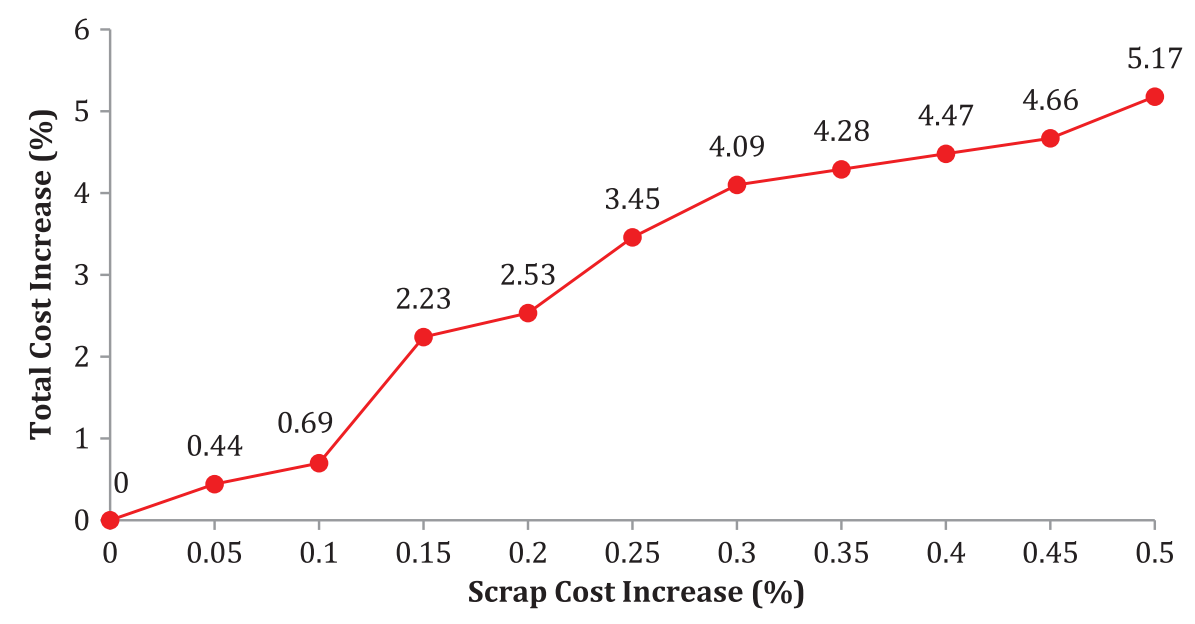

Figure 19. Impact of scrap cost on total cost.

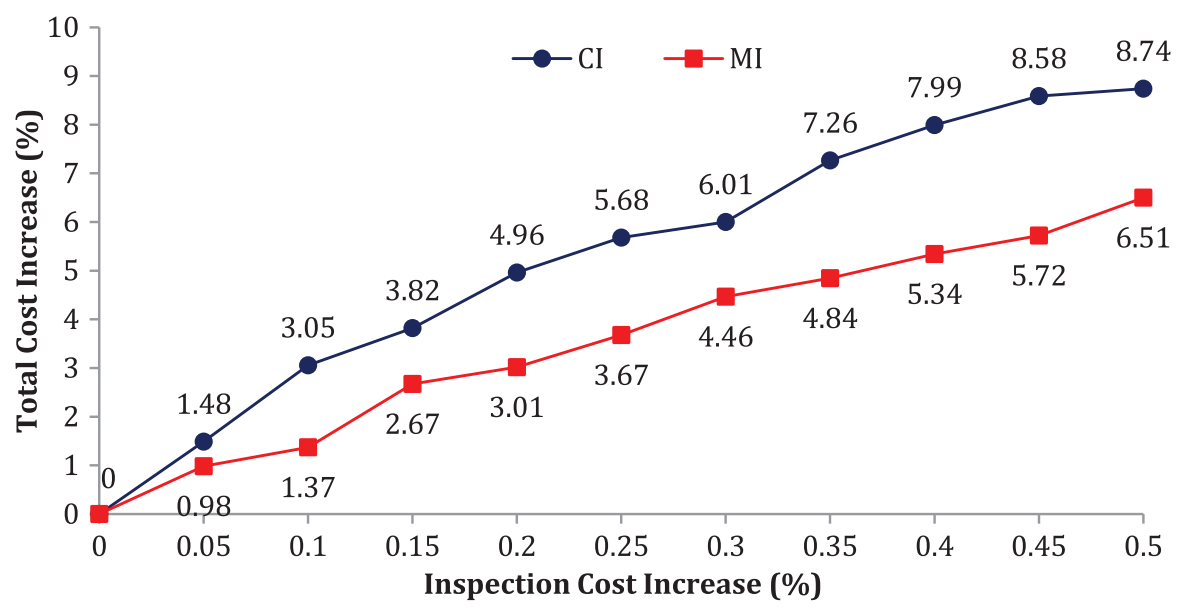

Figure 20. Impact of inspections cost on total cost. 


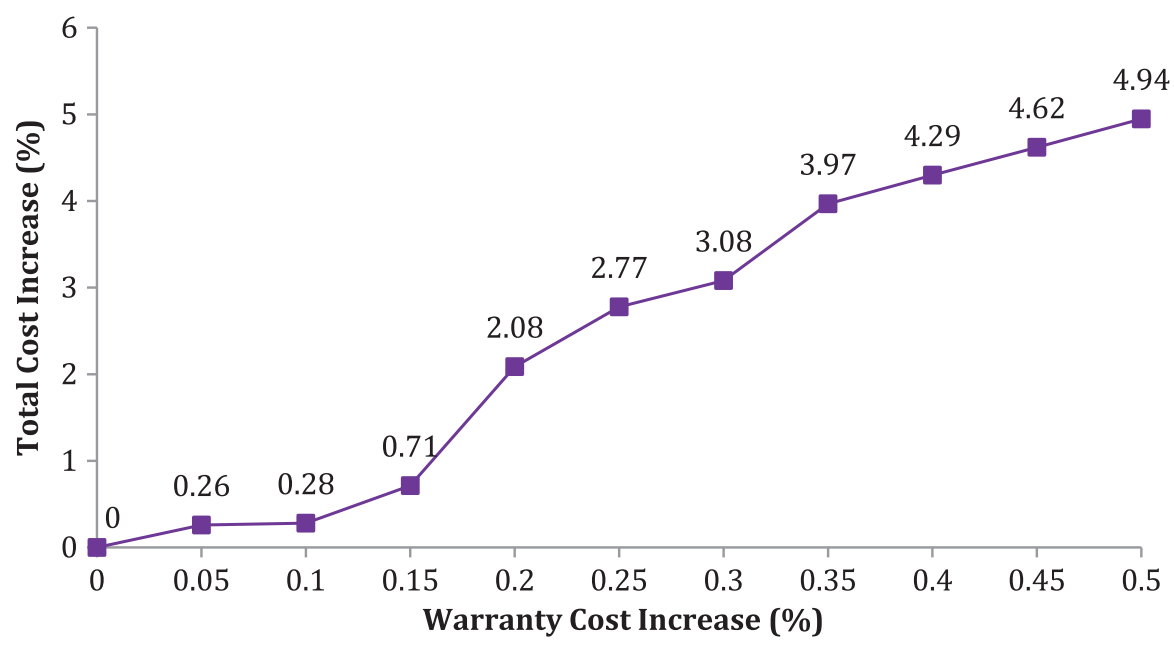

Figure 21. Impact of warranty cost on total cost.

since operation number $7,8,12$ to 15 have the lowest capability, they are selected for performing CI in any case of uncertainty.

Other important results show that extra costs, amount to 920353 (i.e. 6080603-5160250) and 932133 (i.e. $6000253-5068120$ ) are needed to obtain robust solutions for T1 method in both strategies. Similarly, for T2 method, extra costs, amount to 920353 (i.e. 6080603 - 5160250) and 1036643 (i.e. 6104763 - 5068120 ) are needed. Therefore, in order to obtain robust solutions, T2 method is more costly comparing to T1.

Values of manufacturing and warranty cost for each method under both strategies are listed in Table 3, where manufacturing cost is equal to the total cost without the warranty cost. According to Table 2, although the deterministic method under MI-and-CI strategy has lower manufacturing cost (i.e. efficient), it is less responsive regarding customers while its warranty cost is more than MI-or-CI strategy. Similar tithe deterministic method, for T1 and T2, MI-and-CI strategy is efficient, while MI-or-CI has higher responsiveness.

In order to investigate the effect of alteration of different cost-related parameters on the objective function, Figures 18-21 illustrate impact of increase in production, scrap, inspection and warranty costs on the objective function, respectively. Although it is obvious that by increasing the value of the cost-related parameters, the objective function is also increased, but production, inspection, scrap and warranty costs have the highest impact on the objective function value, respectively. It is also noteworthy that despite of scrap and warranty cost, the objective function value is smoothly increased by increasing the production and inspection costs. It means that the objective function is more sensitive to the alteration of scrap and warranty costs. In addition, in Figure 20, it has been shown that increasing the cost of conformity inspection has more effect on the objective function in comparison with monitoring inspection.

\section{Conclusion}

This study proposed a new optimisation framework to design an effective process inspection planning based on a mixed-integer linear programming (MILP) model. Through the proposed MILP, two different kinds of inspection, namely monitoring and conformity inspections, have been taken into account. The main purpose of the proposed MILP model is making a twofold decision on 1) which quality characteristic needs what kind of inspection and 2) when the inspection on these characteristics should be performed. Besides, two different strategies have been considered in the problem, in which limitation of inspection type in the first strategy has been relaxed in the second strategy. The proposed MILP model minimises the total production cost that is the sum of manufacturing and warranty costs. Due to the stochastic nature of production processes, the proposed MILP has been studied under the misadjustment uncertainty. To cope with this uncertainty, two robust optimisation approaches based on Taguchi and Monte Carlo methods have been developed. To achieve optimal solutions under uncertainty for the proposed model, a well-known evolutionary algorithm, namely genetic algorithm (GA), is used. Finally, applying the model on a real industrial case draws the following conclusions: 
- Manufacturing and warranty costs are in conflict in terms of the number of scraps,

- Higher level of misadjustment uncertainty increases the number of scraps,

- Increasing the level of uncertainty increases the number of conformity inspections.

- In the presence of uncertainty, conformity inspection is performed for operations with lower capability,

- An extra cost is charged to design of a robust process inspection plan,

- The responsiveness of the robust solutions are more than deterministic ones,

- The efficiency of the deterministic solutions is more than the robust ones,

- Deterministic solution under the MI-and-CI strategy is more efficient but less responsive comparing to the MI-or-CI strategy,

- Robust solutions of T1 and T2 methods under the MI-and-CI strategy are more efficient but less responsive rather than the MI-or-CI strategy,

- The MI-or-CI strategy should be adopted to enhance customer satisfaction by lowering the number of scraps that are sold to the customers,

- The MI-and-CI strategy should be adopted to reduce the total cost,

- By increasing the value of the cost-related parameters, the objective function is also increased,

- Production, inspection, scrap and warranty costs have the highest impact on the objective function value, respectively,

- Despite of scrap and warranty cost, the objective function value is smoothly increased by increasing the production and inspection costs. It means that the objective function is more sensitive to the alteration of scrap and warranty costs.

Since, alteration of input parameters strongly affects the value of the objective function, designing global robust inspection plans by considering uncertainty in other parameters such as costs, time, dispersion and inspection errors can be a good future research direction.

\section{Acknowledgements}

The authors would like to acknowledge France embassy in Iran and Campus France, the French national agency for the promotion of higher education, international student services and international mobility, for their financial support under the scholarship number $799072 \mathrm{C}$.

\section{References}

Alam, M. R., K. S. Lee, M. Rahman, and Y. F. Zhang. 2003. "Process Planning Optimization for the Manufacture of Injection Molds Using a Genetic Algorithm.” International Journal of Computer Integrated Manufacturing 16 (3): 181-191.

Arvidsson, M., and I. Gremyr. 2008. "Principles of Robust Design Methodology." Quality and Reliability Engineering International 24 (1): $23-35$.

Back, T., F. Hoffmeister, and H.-P. Schwefel. 1991. "A Survey of Evolution Strategies." In Genetic Algorithms. Proceedings of the Fourth International Conference, edited by R. K. Belew and L. B. Booker, 2-9. San Mateo: Morgan Kaufmann.

Bai, D. S., and H. J. Yun. 1996. "Optimal Allocation of Inspection Effort in a Serial Multi-stage Production System.” Computer and Industrial Engineering 30 (3): 387-396.

Barad, M. 1990. "A Break-even quality Level Approach to Location of Inspection Station in a Multi-stage Production Process." International Journal of Production Research 28 (1): 29-45.

Basili, V., and B. Boehm. 2001. "Software Defect Reduction Top 10 List." Computer 34 (1): 135-137.

Beiqing, H., and X. Du. 2006. "A Robust Design Method Using Variable Transformation and Gauss-Hermite Integration." International Journal for Numerical Methods in Engineering 66 (12): 1841-1858.

Beyer, H. G., M. Olhofer, and B. Sendhoff. 2002. "On the Behavior of $(\mu / \mu i, \lambda)$-es Optimizing Functions Disturbed by Generalized Noises." Foundations of Genetic Algorithms 7: 307-328.

Briand, L. C., O. Laitenberger, and I. Wieczorek. 1997. Building Resource and Quality Management Models for Software Inspections. Technical Report. International Software Engineering Research Network ISERN-97-06.

Chakravarty, A. K., and A. Shtub. 1987. "Strategic Allocation of Inspection Effort in a Serial, Multi-product Production System." IIE Transactions 19 (1): 13-22.

Chryssolouris, G. 2005. Manufacturing Systems: Theory and Practice. 2nd ed. 606p. New York: Springer-Verlag.

Das, I. 2000. "Robustness Optimization for Constrained Nonlinear Programming Problems." Engineering Optimization 32 (5): $585-618$.

Desimoni, E., and B. Brunetti. 2011. "Uncertainty of Measurement and Conformity Assessment: A Review." Analytical and Bioanalytical Chemistry 400: 1729-1741. 
Ferreira, R. J. P., A. T. Almeida, and C. Cavalcante. 2009. "A Multi-criteria Decision Model to Determine Inspection Intervals of Condition Monitoring Based on Delay Time Analysis.” Reliability Engineering and System Safety 94: 905-912.

Galbraith, J. 1973. Designing Complex Organizations. Reading, MA: Addison Wesley.

Goldberg, D. E. 1989. Genetic Algorithms in Search, Optimization, and Machine Learning. Reading, MA: Addison-Wesley.

Gyung-Jin, P., and K. H. Lee. 2002. "Robust Optimization in Discrete Design Space for Constrained Problems." AIAA Journal 40 (4): 774-780.

Gyung-Jin, P., T. H. Lee, K. H. Lee, and K. H. Hwang. 2006. "Robust Design: An Overview." AIAA Journal 44 (1): $181-191$.

Hanne, T., and S. Nickel. 2005. "A Multiobjective Evolutionary Algorithm for Scheduling and Inspection Planning in Software Development Projects." European Journal of Operational Research 167: 663-678.

Hans-Georg, B., and Bernhard Sendho. 2007. "Robust Optimization - A Comprehensive Survey." Computer Methods in Applied Mechanics and Engineering 196 (33-34): 3190-3218.

Hurst, E. 1973. "Imperfect Inspection in a in a Multi-Workstation Production Process." Management Science 20: 378-384.

Hinrichs, W. 2011. "Product-specific Adaption of Conformity Assessment Criteria and Their Financial Consequences." Journal of Production Engineering Research and Development 5: 549-556.

Ho, C. 1989. "Evaluating the Impact of Operating Environments on MRP System Nervousness." International Journal of Production Research 27: 1115-1135.

Holland, J. H. 1975. Adaption in Natural and Artificial Systems. Ann Arbor: University of Michigan Press.

Jin, Y., and B. Sendhoff. 2003. "Trade-off between Performance and Robustness: An Evolutionary Multiobjective Approach." Lecture Note in Computer Science 2632: 237-251.

Kallgren, H., M. Lauwaars, B. Magnusson, L. Pendrill, and Ph Taylor. 2003. "Role of Measurement Uncertainty in Conformity Assessment in Legal Metrology and Trade." Accreditation and Quality Assurance 8: 541-547.

Kane, V. E. 1986. "Process Capability Indices.” Journal of Quality Technology 18 (1): 41-52.

Kunzmann, H., T. Pfeifer, R. Schmitt, H. Schwenke, and A. Weckenmann. 2005. "Productive Metrology - Adding Value to Manufacture." CIRP Annals - Manufacturing Technology 54 (2): 155-168.

Lee, H., and S. S. Kim. 2001. "Integration of Process Planning and Scheduling Using Simulation-based Genetic Algorithms." International Journal of Advanced Manufacturing Technology 18: 586-590.

Lee, J., and S. Unnikrishnan. 1998. "Planning Quality Inspection Operations in Multistage Manufacturing Systems with Inspection Errors.” International Journal of Production Research 36 (1): 141-155.

Lindsay, G. F., and A. B. Bishop. 1964. "Allocation of Screening Inspection Effort - Dynamic Programming Approach." Management Science 10 (2): 343-352.

Michael, W. T. 1996. "Taguchi and Robust Optimization.” Technical Report. Houston, TX: Department of Computational \& Applied Mathematics, Rice University.

Mirdamadi, S., A. Etienne, A. Hassan, J. Y. Dantan, and A. Siadat. 2011. "Cost Estimation Method for Variation Management." 12th CIRP Conference on Computer Aided Tolerancing, Huddersfield, April 18-19.

Munch, J., T. Berlage, T. Hanne, H. Neu, S. Nickel, S. von Stockum, and A. Wirsen. 2002. Simulation-based Evaluation and Improvement of SW Development Processes. SEV Progress Report No. 1. Kaiserslautern: Fraunhofer IESE.

Neu, H., T. Hanne, J. Munch, S. Nickel, and A. Wirsen. 2002. "Simulation-based Risk Reduction for Planning Inspections." In Product Focused Software Process Improvement, Lecture Notes in Computer Science, edited by M. Oivo and S. Komi-Sirvio, Vol. 2559, 78-93. Berlin: Springer.

Neu, H., T. Hanne, J. Munch, S. Nickel, and A. Wirsen. 2003. "Creating a Code Inspection Model for Simulation-based Decision Support." Paper presented at ProSim _03, Portland State University, Portland, OR, May 3-4.

Peters, M. H., and W. W. Williams. 1984. "Location of Quality Inspection Stations: An Experimental Assessment of Five Normative Heuristics." Decision Science 15 (3): 389-408.

Pfeiffer, T. 2002. Production Metrology. Oldenbourg: Walter de Gruyter. ISBN 3486258850.

Savio, E. 2012. "A Methodology for the Quantification of Value-adding by Manufacturing Metrology." CIRP Annals - Manufacturing Technology 61: 503-506.

Shiau, Y. R. 2002. "Inspection Resource Assignment in a Multistage Manufacturing System with Inspection Error Model." International Journal of Production Research 40 (8): 1787-1806.

Shiau, Y. R. 2003a. "Inspection Allocation Planning for a Multiple Quality Characteristic Advanced Manufacturing System." International Journal of Advanced Manufacturing Technology 21: 494-500.

Shiau, Y. R. 2003b. "Quick Decision-making Support for Inspection Allocation Planning with Rapidly Changing Customer Requirements." International Journal of Advanced Manufacturing Technology 22 (9-10): 633-640.

Shiau, Y. R., M. H. Lin, and W. C. Chuang. 2007. "Concurrent Process/Inspection Planning for a Customized Manufacturing System Based on Genetic Algorithm." International Journal of Advanced Manufacturing Technology 33: 746-755.

Shukla, N., M. K. Tiwari, and D. Ceglarek. 2013. "Genetic-algorithms-based Algorithm Portfolio for Inventory Routing Problem with Stochastic Demand.” International Journal of Production Research 51 (1): 118-137.

Taha, H. A. 2006. Operations Research: An Introduction. Englewood Cliffs, NJ: Prentice-Hall.

Torben, H., M. Arvidsson, and I. Gremyr. 2009. "A Review of Practices for Robust Design Methodology." Journal of Engineering Design 20 (6): 645-657. 
Viswanadham, N., S. M. Sharma, and M. Taneja. 1996. "Inspection Allocation in Manufacturing Systems Using Stochastic Search Technique." IEEE Transactions on Systems, Man, and Cybernetics - Part a: Systems and Humans 26 (2): $222-230$.

Wei, C., J. K. Allen, K. L. Tsui, and F. Mistree. 1996. “A Procedure for Robust Design: Minimizing Variations Caused by Noise Factors and Control Factors." Journal of Mechanical Design 118 (4): 478-485.

White, L. S. 1966. "The Analysis of a Simple Class of Multistage Inspection Plans.” Management Science 12 (7): 685-693.

Xiaoping, D., and W. Chen. 2000. "Methodology for Managing the Effect of Uncertainty in Simulation-based Design." AIAA Journal 38 (8): 1471-1478.

Yum, B. J., and E. D. McDowell. 1987. "Optimal Inspection Policies in a Serial Production System including Scrap Rework and Repair: An MILP Approach.” International Journal of Production Research 25 (8): 1451-1464.

Zhao, F., X. Xu, and S. Q. Xie. 2009. “Computer-aided Inspection Planning-the State of the Art.” Computers in Industry 60: $453-466$. 